\title{
El poder y los valores en Weber, Freud y Kelsen, a la luz del "nuevo paradigma científico" y en relación con América Latina
}

\author{
Eda Cleary \\ Consultora en cuestiones sobre el desarrollo social y modernización del Estado para GTZ, \\ Managua. Nicaragua. Email: edacleary@yahoo.co.uk
}

Resumen: El presente trabajo intentará aproximarse críticamente a la revisión del concepto del "poder” en relación a los valores del hombre, a partir de las teorías desarrolladas por tres maestros universales clásicos de las ciencias sociales y psicoanalíticas como fueron Max Weber, Sigmund Freud y Hans Kelsen. Nuestra hipótesis consiste en afirmar que los aportes teóricos de estos tres autores conservan su validez hasta la actualidad y enriquecen las tesis derivadas del "nuevo paradigma científico" con respecto a las actuales formas de organización del "poder" en redes. Sobre todo en lo que respecta a su doble abordaje acerca del "poder”: el análisis de sus estructuras y el origen de los valores que lo sustentan desde sus bases antropológicas. Al concluir se reflexiona acerca de la validez de este pensamiento para la historia moderna de América Latina.

Palabras clave: poder, valores, paradigma científico.

\section{Power and values in Weber, Freud and Kelsen in the light of the "new scientific paradigm" and in relation to Latin America}

\begin{abstract}
This paper will attempt to approach critically a review of the concept of "power» in relation to human values, from the theories developed by three classic universal teachers of social sciences and psychoanalysis as were Max Weber, Sigmund Freud and Hans Kelsen. Our hypothesis is the claim that the theoretical contributions of these three authors remains valid until present time and enrich the thesis derived from the "new scientific paradigm" with respect to current forms of organization of "power" in networks. Especially in regard to its dual approach about "power": the analysis of its structures and the origin of the values that sustains it from its anthropological bases. When concluding, an nalysis is done on the validity of this thinking for Latin America's modern history.

Key words: power, values, scientific paradigm.
\end{abstract}

\section{O poder e os valores em Weber, Freud e Kelsen à luz do “novo paradigma científico" e em relação à América Latina}

Resumo: Este trabalho vai tentar abordar uma revisão crítica do conceito de “poder” em relação aos valores humanos a partir das teorias desenvolvidas por 
três professores clássicos universais das ciências sociais e da psicanálise como foi Max Weber, Sigmund Freud e Hans Kelsen. Nossa hipótese é a afirmação de que as contribuições teóricas dos três autores permanecem válidos até os dias atuais e enriquecem as teses derivadas do "novo paradigma" no que diz respeito às formas atuais de organização do "poder" nas redes. Especialmente no que diz respeito à sua dupla abordagem sobre o "poder": a análise das suas estruturas e da origem dos valores que o sustentam a partir de suas bases antropológicas. Na conclusão reflete-se sobre a validade deste pensamento para a história moderna da América Latina.

Palabras-chave: poder, valores, paradigma científico.

$$
* * *
$$

\section{Introducción}

El presente trabajo intentará aproximarse críticamente a la revisión del concepto del "poder" en relación a los valores del hombre a partir de las teorías desarrolladas por tres maestros universales clásicos de las ciencias sociales y psicoanalíticas como fueron Max Weber, Sigmund Freud y Hans Kelsen. Nuestra hipótesis consiste en afirmar que los aportes teóricos de estos tres autores conservan su validez hasta la actualidad y enriquecen las tesis derivadas del "nuevo paradigma científico" con respecto a las actuales formas de organización del "poder” en redes. Sobre todo en lo que respecta a su doble abordaje acerca del "poder”: el análisis de sus estructuras y el origen de los valores que lo sustentan desde sus bases antropológicas.

Este ensayo se compondrá de tres capítulos: en el primero haremos una breve referencia de la obra de nuestros tres autores. Luego propondremos los “prototipos de hombre” subyacentes a los estudios de Weber, Freud y Kelsen como base para abordar sus conceptos de “poder” y los valores en forma comparativa y complementaria; En el segundo capítulo presentaremos algunas reflexiones sobre la cuestión del "poder" en el contexto de "nuevo paradigma científico” y las características de las formas de organización social en redes; y en el tercer capítulo apuntaremos algunos temas atingentes al “poder” y la situación política actual en América Latina, el rol del Estado de derecho, la racionalidad en los estilos de vida y la cuestión del control de la violencia.

\section{El concepto del poder y los valores en Weber, Freud y Kelsen}

\section{Sobre Weber, Freud y Kelsen}

Max Weber (1864-1920), Sigmund Freud (1856-1939) y Hans Kelsen (1881-1973) son científicos universales que ha dado la historia, cuyas huellas se hacen sentir hasta el día de hoy en lo que respecta a la comprensión de la vida del hombre moderno. 
Max Weber fue jurista, economista, sociólogo y politólogo alemán. Es el fundador de la sociología comprensiva y se destacó por su monumental obra plasmada en "Economía y Sociedad” (Wirtschaft und Gesellschaft), donde estudió la especificidad de la economía capitalista a partir de sus orígenes culturales, religiosos, formas de vida y el análisis del tipo de "poder" prevaleciente en esta etapa del desarrollo histórico. Fue un erudito que abarcó el estudio de los fenómenos sociales de su tiempo sobre la base de un conocimiento profundo de las sociedades antiguas de la China, de la India, de Europa y de América.

Su obra más famosa se tituló “La ética protestante y el espíritu del capitalismo” (1915). Esta publicación causó un revuelo tan grande en los círculos de las ciencias sociales y económicas que su influencia dura hasta el día de hoy. La discusión en torno a este libro ha sido llamada "la guerra de los cien años” y ha dado lugar a una infinita producción de libros interpretativos, ya que la asociación del vínculo entre religión y economía puso de manifiesto la importancia central de los valores de las personas dentro de su conducta económica.

Weber se caracterizó en su época por dar la lucha contra la predominancia de las visiones del mundo (Weltanschauungen) de cualquier índole como fundamento para el desarrollo de las teorías sociales, pues ellas no podían ser comprobadas empíricamente y pertenecían al mundo de la filosofía o de la política. Fundó un concepto de sociología que apuntaba a comprender y entender lo que pasaba en la realidad y no a transformarla, ya que eso requería de una convicción filosófica que se movía fuera del ámbito de la ciencia. Weber es considerado uno de los fundadores de la sociología moderna, pues tanto su metodología como su visión del papel que debía cumplir la ciencia social como una ciencia empírica y libre de juicios de valor (werturteilsfrei) son válidas universalmente para la investigación social en los círculos científicos del mundo. Entre los temas más relevantes en la obra de Weber se cuentan: la racionalidad de la cultura occidental moderna, la economía, el derecho, el rol de la burocracia en la democracia moderna, el papel de la religión en la cultura, la política como profesión, y sus estudios sobre los tipos y fuentes de legitimación del "poder” y de la dominación.

Sigmund Freud, médico y neurólogo austríaco, fue contemporáneo de Weber y fundador del Psicoanálisis. Se convirtió en una de las mayores figuras intelectuales del siglo XX. Desarrolló una teoría de la mente por niveles y de la conducta humana ayudando a desentrañar las claves fundamentales del funcionamiento psíquico humano. Asimismo elaboró una técnica terapéutica para ayudar a curar enfermedades psíquicas.

Sus ideas resultaron revolucionarias, debido a que intentó darle un carácter científico al concepto de “lo inconsciente”, que había tomado de Schopenauer y Nietzsche. A partir de su concepto del "inconsciente" (deseo inconsciente y represión), propuso la idea de una mente dividida en capas o niveles, dominada en cierta medida por una voluntad primitiva in- 
herente a la naturaleza humana compuestas de los instintos de muerte y el Eros que iban más allá de lo consciente y que se manifestaban en medio de la represión civilizatoria en forma de signos, bromas, lapsus, actos fallidos, sueños y síntomas.

Freud no sólo se limitó a estudiar la psicología humana individualmente, sino que vio con una claridad premonitoria los efectos que la "libido"1 podía tener sobre los individuos como parte de una masa que adopta conductas colectivas afirmándose principalmente en el inconsciente. Sus investigaciones de la conducta colectiva de las masas, lo llevaron a descubrir que los humanos realizan una verdadera regresión hacia las formas de vida de la "horda primitiva"2, donde las pulsiones agresivas y de hostilidad, de amor o de sumisión podían adoptar formas peligrosas para la vida civilizada.

Entre sus obras más destacadas se cuentan "La interpretación de los sueños” (1900), “Totem y Tabú” (1913-1914), “Más allá del principio del placer” (1920), “La Psicología de las Masas y el análisis del yo” (1921) y “El Malestar en la cultura” (1929). A pesar que su pensamiento nunca estuvo libre de controversia y de detractores, actualmente la obra de Freud sigue ocupando un lugar importante en el psicoanálisis moderno aunque sus teorías han sido reinterpretadas por generaciones de nuevos psiquiatras y psicoanalistas ${ }^{3}$.

Hans Kelsen, jurista, filósofo y juez austríaco, jugó un papel crucial en la modernización de la teoría del derecho del siglo XX. Planteó una estricta separación entre el derecho y la moral para consagrar un tipo de derecho científico que hiciera abstracción de toda consideración ética, filosófica, social o histórica. Su idea del “poder” estatal como una estructura de normas jerárquicamente organizada, pero dinámica ${ }^{4}$, susceptible de modificar, marcó una nueva etapa en la historia del pensamiento jurídico.

Para Kelsen el derecho es el Estado y el Estado es el derecho ${ }^{5}$. Según su planteamiento toda norma jurídica emana de otra norma y todas surgen a partir de la "norma fundamental" (Grundnorm) de tipo transcendental y que presupone la validez autónoma del derecho. El derecho no discute los contenidos de las normas, sino sólo la forma en que se generan y sus procedimientos.

Estas ideas las sistematizó en la “Teoría Pura del Derecho” (Reine Rechtslehre) (1935), una obra positivista jurídica. Una de sus principales preocupaciones era evitar los abusos de "poder" cometidos por sistemas judiciales que en nombre del así llamado “interés general”, “razón de Estado” pretendían otorgarle un fundamento objetivo a un accionar subjetivo guiado por intereses personales. Para Kelsen “...no existe doctrina que pueda ser eliminada en nombre de la ciencia, pues el alma de la ciencia es la tolerancia” ${ }^{6}$. Desde el punto de vista del conocimiento racional, solo reconocía intereses humanos y conflictos de interés que debían ser resueltos estableciendo un equilibrio entre ambos si es que se eligiera la paz social como valor supremo. 
Partiendo del relativismo de los valores, Kelsen consideró la democracia como una forma de organización social que promovía la tolerancia y con ello garantizaba de mejor manera la paz necesaria para la convivencia humana.

Se destacó por sus ideas de revisión de la Constitución proponiendo la creación de los Tribunales Constitucionales como un cuerpo de jueces que no provengan del "poder" judicial y que esté facultado para anular normas que entren en contradicción con la constitución transformándose así en parte del "poder" legislativo, pero como un "legislador negativo". Entre las obras más destacadas de Hans Kelsen mencionamos "La teoría Pura del Derecho” (1935), "Socialismo y Estado” (1920), “Dios y el Estado” (1922-1923) , "Esencia y Valor de la Democracia” (1929), “El Derecho de las Naciones Unidas” (1950) y la “Teoría General de las Normas” (1979, obra póstuma).

Dentro de la literatura disponible, no se encuentran testimonios sobre algún encuentro personal entre Weber y Freud aunque hayan sido contemporáneos. Diferente es la relación en el caso de Kelsen, ya que él estudió la obra de Weber y de Freud en profundidad y conoció personalmente a ambos. Famosa fue su controversia con Max Weber en torno a la sociología del derecho. Aunque ambos autores eran positivistas, sus opiniones se diferenciaban a la hora de definir la relación entre Estado y derecho. Mientras Weber consideraba al Estado moderno como un ordenamiento jurídico que garantizaba el "poder” por medio de la coacción física, Kelsen, en cambio, planteaba que el Estado desaparecía como una entidad diversa al derecho cuando éste último regulaba su propio accionar.

Para Kelsen no era el "poder" mediante la coacción física lo que definía al Estado, sino que éste se explicaba mediante la realización del derecho y el contenido de las normas jurídicas ${ }^{7}$. Además enriqueció con las teorías psicoanalíticas de Freud la comprensión del tema de los valores y naturaleza humana como motores del accionar social. De la misma manera reflexionó sobre el Estado desde el concepto psicoanalítico de la "masa", indagando si estas dos formaciones sociales tendrían características similares. En 1922 publicó el ensayo titulado "El Concepto del Estado y la Psicología Social, teniendo como referencia especial la teoría de las masas según Freud”.

Lo importante para el presente trabajo es la relectura de las obras de Weber, Freud y Kelsen en torno al tema que nos interesa que es el concepto del "poder" y su fundamento valórico. Con el objeto de abordar estos temas en forma conjunta, presentaremos los "prototipos de hombre" subyacentes al pensamiento de estos autores y discutiremos sobre sus estilos de vida y el tipo de vínculo que establecen con el "poder".

\section{Tres prototipos de hombre}

Para identificar los prototipos de hombre en las obras de nuestros autores, hay que considerar que los tres se referían esencialmente al hom- 
bre moderno occidental en el contexto del capitalismo moderno basado en el uso de la ciencia y la tecnología y la presencia de un Estado con el "poder” monopólico de la coerción física.

El centro de las investigaciones de nuestros tres autores fue el individuo dentro de un mundo interrelacionado y vinculado por relaciones de "poder" en todos los planos de la vida en sociedad: la economía, la cultura, la familia, la religión, el trabajo, la ciencia y la política. En este marco observaron que el individuo moderno, con sus pretensiones de libertad y autodeterminación, entraba necesariamente en contradicción con un sistema de organización social burocrático estricto que exigía cada vez mayores niveles de regulación de la conducta humana a través de sus diversas instituciones.

En la lucha permanente por ser funcional al sistema y obtener el “éxito", el hombre no sólo debía responder a las exigencias externas de la civilización misma, sino que tenía que generar capacidades de "autocontrol" para contener los desequilibrios emocionales que pudieran amenazar con desbordar los límites de la nueva racionalidad imperante. La manera sobre cómo el ser humano buscaba salidas para sobrevivir como sujeto emocional en este tenso escenario, ha sido sin duda un tema clave dentro de las obras de Weber, Freud y Kelsen, aunque las hayan abordado desde tres diferentes áreas del conocimiento.

Los prototipos de individuos subyacentes al pensamiento de Weber, Freud y Kelsen, son a nuestro juicio, los siguientes: para Weber el "hombre burocrático", para Freud el "hombre neurótico” y para Kelsen el "hombre jurídico".

\section{El "hombre burocrático" de Weber}

Este prototipo de hombre podría denominarse también el "hombre racional instrumental”. Sin embargo, nos concentraremos en el aspecto de la burocracia por considerarlo de mayor relevancia a la hora de entender las condiciones de su desenvolvimiento personal descritas por Weber.

Conviene recordar que Weber era un pensador cuyas posiciones crearon una gran controversia dentro del mundo académico de su época, predominantemente dominado por el "caos" entre diferentes visiones del mundo (Weltanschauungen) que se contraponían en su lucha por definir la verdad. Weber en cambio, defendía una ciencia social "libre de juicios de valor" (Werturteilsfreiheit) y no creía en postulados políticos o filosóficos de corte mesiánico religioso o ateo. Vió como "profecías patéticas” el ideal marxista ${ }^{8}$ de la sociedad comunista, y de la sociedad del amor de los cristianos, donde no habría conflictos de ninguna especie y donde reinaría la felicidad y la justicia. Para Weber eran visiones del mundo que no soportaban la prueba de la comprobación empírica y que pertenecían al mundo de los deseos subjetivos. 
Su metodología apuntaba a la comprensión y explicación de la "acción social” ('soziales Handeln’ unidad básica del método de la sociología comprensiva) por medio de "tipos ideales" (Idealtypen) que eran categorías promedio de "acción social” extraídas de la realidad misma, para interpretarla y explicarla causalmente en el entramaje social, cuyo actor principal era el individuo. Weber afirmaba que "sin 'acción social' del individuo no hay sociedad”.

El concepto de burocracia weberiano ${ }^{9}$, no es como muchas veces se ha creído erróneamente, un modelo propuesto, sino que es exclusivamente la descripción de un tipo concreto de cuadro administrativo del "poder" estatal en las sociedades más modernas del capitalismo occidental (pero también de las asociaciones de cualquier especie) que va moldeando un tipo de individuo funcional al sistema. No se trata de calificar a la burocracia moderna como un modelo "ideal” de administración de la sociedad de masas y de la aplicación del "poder" estatal en el sentido normativo, sino que solamente de entender su proceso de profesionalización y tecnificación sobre bases racionales, como la selección óptima de los instrumentos adecuados para "dominar" en forma más "eficiente” y "eficaz" a una población cuyo modo de vida planteaba cada vez desafíos más complejos.

Cabe subrayar, no obstante que, a pesar de la predominancia de este estilo de vida (Lebensführung) cruzado por la burocracia, eminentemente racional-instrumental (zweckrational), Weber no dejó de ver al ser humano como protagonista de una constante lucha con sus emociones, pues reconocía una mezcla de causas que determinaban la acción social del hombre moderno más allá de la racionalidad instrumental como eran los afectos, los principios y las tradiciones ${ }^{10}$. El hombre oscilaba entre la nostalgia por un mundo pasado dominado por las supersticiones, magia y la búsqueda de la salvación extraterrenal y el mundo moderno, donde todo era calculable y previsible. En el mundo moderno se trataba solamente de ponerse unos objetivos ponderando los medios óptimos para lograrlos y adelantándose a cualquier efecto secundario no deseado. A este fenómeno, donde la eficiencia y eficacia del accionar social confinaba la fe religiosa a un lugar secundario en la vida del hombre, despojándolo del arrullo de la creencia en lo mágico y del más allá, Weber lo llamó el "desencantamiento del mundo” (“Entzauberung der Welt”).

La racionalidad occidental había logrado regular todos los ámbitos de la vida humana y fue así justamente como fue surgiendo el hombre moderno. Su existencia estaba destinada a una estricta regulación en un marco de "poder" legal, desprovisto ya de una espiritualidad y sentido íntimo de la vida.

Weber nunca tuvo una posición hostil hacia la cultura ya que veía el avance del racionalismo occidental como un proceso irrefrenable e inevitable. Haciendo frente a la "violenta seriedad" (gewaltiger Ernst) de este estado de cosas, Weber estaba convencido que aquel que quisiera conocer al mundo y comprenderlo debía atenerse a estas circunstancias: "el que 
quiera espectáculo que vaya al cine,... el que quiera sermones que vaya al monasterio” ( Wer Schau wünscht, gehe ins Lichtspiel,... wer Predigt wünscht, gehe ins Konventikel) ${ }^{11}$, pero aquel que quiera entender los motivos de por qué la sociedad funciona así y no de otra manera, debía ceñirse a un tipo de pensamiento ligado a la ciencia de los hechos objetivos y sus posibilidades técnicas de aplicación en lapsos históricos delimitados

Sus famosas frases": Fachmenschen ohne Geist” ( técnicos sin espíritu) y "Genußmenschen ohne Herz" (hedonistas sin corazón) ${ }^{12}$ resumen en una frase al "hombre burocrático" del que hablábamos al principio de este capítulo. Fiel a sus postulados, su intención no era emitir un juicio de valor, sino que solamente describir "lo que es" sobre la base del análisis del entramaje de acciones sociales en la sociedad moderna, que son irrefutables: la uniformación de la conducta y el estilo de vida en pos del aumento de la riqueza material.

El "hombre burocrático" de Weber es un personaje inserto en un sistema de "dominación" de alta legitimidad, ya que la autoridad política logra conseguir la obediencia voluntaria de los ciudadanos por la fuerza arrolladora del "poder" regulador de su aparato burocrático y del monopolio estatal de la coacción física.

Weber estaba convencido que la integración a la sociedad racional instrumental, y la salida para el alivio de sus efectos negativos, pasaba por generar una capacidad de aceptación de lo inevitable soportando estoicamente sus desventajas y aprovechando sus posibilidades sobre la base de la decisión individual de limitarse a pensar dentro de la lógica instrumental, sin ayuda externa. Es decir, Weber retomaba una argumentación similar a la del "árbitro interno" (the inhabitant of the breast, the man within, the great judge and arbiter of our conduct) ${ }^{13}$ del clásico de la economía liberal y filosofía moral Adam Smith (1723-1790), que estaría alojado en el alma de la persona para ayudarlo a regular sus "sentimientos morales” en medio de una sociedad burguesa que mostraba síntomas de decadencia moral y no lograba generar en el ser humano la humanidad necesaria para convivir en paz. Cuando hablaba de la "great school of selfcommand" ${ }^{14}$, Smith no veía otra técnica de manejo emocional en la adversidad, que la búsqueda individual de un equilibrio interno o íntimo entre valores contrapuestos que pugnan por imponerse ${ }^{15}$.

Algo parecido encontramos en las obras weberianas "La ciencia como profesión” (1918) y “La política como profesión” (1919). En ésta última Weber presentaba al individuo político enfrentado a las contradicciones del "poder” de la siguiente manera: “... el demonio de la política convive con el Dios del amor, (...) en una tensión interna, que puede desencadenar un conflicto irreconciliable en cualquier momento" 16 . Esto sobre todo cuando la ética de los principios (Gesinnungsethik) no mide sus consecuencias y deja de lado la "ética de la responsabilidad “ (Verantwortungsethik) provocando daños irreparables. Weber planteaba que el político profesional solo podía ser aquel que combinara estas dos éticas 
en forma equilibrada ${ }^{17}$ por la fuerza de la voluntad personal.

El tema de los valores tuvo un significado central en la sociología comprensiva de Weber. Las visiones del mundo determinaban la manera en que los individuos se relacionaban tanto a nivel personal como social aún con la presencia de un “poder” burocrático con pretensiones uniformadoras de la conducta humana. Por esta razón las investigaciones weberianas nunca dejaron de lado el juego subjetivo entre racionalidad e irracionalidad, entre conflicto social y conflicto individual a pesar de su carácter positivista.

\section{El "hombre neurótico” de Freud}

Para Sigmund Freud la psicología individual siempre era, en un sentido amplio, psicología colectiva porque en la vida anímica individual aparecía siempre integrado “el otro”, ya sea como modelo, objeto, auxiliar o adversario. De esta manera la psicología colectiva considera al individuo como miembro de una tribu, pueblo, clase social, casa, institución o como elemento de una multitud humana que en algún momento y con una determinada finalidad se organiza en una masa o en una colectividad ${ }^{18}$.

Partiendo de esta convicción, Freud investigó las analogías existentes entre los mecanismos de la conducta neurótica individual con los de la colectiva y planteó la posibilidad de que la evolución de la civilización o cultura también podría analizarse en función de un super-yo, o conciencia colectiva. Enunció el concepto de "neurosis colectiva" o de "neurosis social”, pensando que las sociedades se tornaban "neuróticas” bajo la "presión de las ambiciones culturales"19 que no eran otra cosa que la presión para que los individuos reprimieran sus naturales instintos eróticos y agresivos de tal manera que la existencia de la civilización se garantizara.

En la búsqueda de la felicidad (placer), como parte natural en la evolución del individuo, el hombre estaba siempre enfrentado a dos tendencias contrapuestas: Una "egoísta” que representaba la búsqueda de la felicidad individual y otra "altruista” que significaba el anhelo de fundirse con los demás. Sin embargo, la presión de la cultura desplazaba cada vez más el objetivo de alcanzar la "felicidad individual" en pos de la felicidad colectiva. Dicho más categóricamente en las palabras de Freud en "El malestar de la Cultura”: “... casi pareciera que la creación de una gran comunidad humana podría ser lograda con mayor éxito si se hiciera abstracción de la felicidad individual”. Es este hecho el que desataría una lucha sin cuartel entre el individuo y la cultura, cada uno disputándose los espacios y combatiendo por adjudicarse la mayor parte en el reparto de la libido ${ }^{20}$.

En la búsqueda de un equilibrio entre sus propios objetivos y los de la cultura, el hombre moderno de debatiría en una lucha entre la adaptación a las exigencias sociales, su rechazo o negación. Freud observó que cuando el individuo no lograba manejar este conflicto, muy a menudo desarrollaba 
conductas neuróticas. Si la presión por la adaptación al colectivo sobrepasaba las fuerzas del yo creando infelicidad, el individuo tenía generalmente dos salidas: o se rebelaba o hacía una "neurosis". Por ello, proponemos como prototipo del hombre civilizado de Freud al "hombre neurótico", pues según esta visión éste sólo podía vivir en la cultura aprendiendo a reprimir su natural agresividad para darle prioridad, por presión externa, al Eros. Mientras la cultura le exigía organizar su vida en torno al amor, relegando su natural instinto de agresión, el hombre se veía conminado a existir en una continua tensión por la negación de su propia naturaleza desarrollando insoportables sentimientos de culpa, remordimientos y temores frente a la posibilidad de perder el amor. La cultura, para garantizar su existencia, habría impuesto, la desviación del natural instinto de agresión en contra de los demás, hacia una agresión en contra de sí mismo en forma del super-yo o de conciencia moral.

La severidad de esta conciencia moral en el ámbito societal, exigía del individuo cada vez mayores esfuerzos de adaptación al grupo y el individuo ya no se contentaba con autocontrolarse, sino que demandaba a los demás autocontrolarse igualmente y subyugarse a un orden colectivo posponiendo o descalificando la búsqueda de la felicidad individual lo que fomentaba necesariamente el surgimiento de personalidades autoritarias y autoreferentes.

Freud calificó de "cuento de hadas"21 la idea roussoniana o marxista acerca del origen "bueno” del hombre que sólo se veía pervertido por la acción de la civilización. Sus investigaciones concluían que el instinto de muerte era como una “... innata inclinación del hombre hacia 'lo malo', a la agresión, a la destrucción y con ello también a la crueldad”. La evolución cultural la veía como la “...lucha de la especie humana por la vida” aún si era con el costo de la aparición del hombre "neurótico"22 , un ser despojado de los mecanismos propios para encontrar un equilibrio entre el yo y el inconsciente por sí mismo. Ni siquiera los progresos técnicos que aliviaban la vida cotidiana y la alargaban, podían resolver la cuestión del sentido íntimo de la existencia, pues el hombre moderno no cesaba de preguntarse : "De qué nos sirve, por fin, una larga vida si es tan miserable, tan pobre en alegrías y rica en sufrimientos que sólo podemos saludar a la muerte como felíz liberación?”23.

Tanto para Freud como para Weber el hombre moderno era un sujeto fuertemente autocontrolado. En los dos casos, el hombre ponía sus esfuerzos de autocontrol emocional al servicio del sistema productivo. Dentro de esta lógica, planteamos que el "hombre burocrático" de Weber se transforma en el "neurótico" de Freud cuando las presiones de la legalidad burocrática estatal le obligan constantemente a posponer el objetivo de la felicidad individual para conservar el orden social.

Desde el punto de vista de la cuestión del “poder”, las obras de Freud y de Weber pueden ser analizadas complementariamente. Mientras Freud consideraba al individuo inserto en la masa como partícipe de un 
carácter colectivo ajeno a su individualidad que se sometía en forma neurótica al líder de turno, Weber analizaba el papel de los individuos en sociedad con su lógica de dominación de unos sobre otros como expresión de un tipo de organización jerárquica funcional a la racionalidad instrumental occidental. Ambos tipos de hombre actuaban en función de las jefaturas, ya sea representadas por la idea de una lógica o los mandatos de un líder.

Freud había trabajado sistemáticamente en el tratamiento de neurosis individuales a través de psicoterapias personales. Al investigar esta patología en su dimensión social, sabía que era necesario buscar otro método de sanación, sin embargo no llegó a desarrollarlo. El dilema existencial del hombre moderno quedaba así sin una perspectiva de solución. Tal como a través de la psicoterapia el paciente lograba recuperar la capacidad de vivir dentro de la civilización manejando las culpas y patologías derivadas de sus impulsos más primitivos, el sujeto colectivo, es decir la sociedad, no era susceptible de tratar por ese camino. Por este motivo, los prototipos de hombre de Freud y Weber estaban condenados a la soledad de sus decisiones personales para sanarse de los efectos civilizatorios negativos de la cultura moderna.

A juicio de Freud el destino de la humanidad dependía de “... hasta qué punto el desarrollo cultural logrará hacer frente a las perturbaciones de la vida colectiva emanadas del instinto de agresión y de autodestrucción" ${ }^{24}$ en medio de un irrefrenable dominio de las fuerzas de la naturaleza con ayuda de la ciencia y la tecnología.

\section{El “hombre jurídico” de Kelsen}

Hans Kelsen conocía estas teorías en profundidad. Con Freud coincidía acerca de la naturaleza cruel del ser humano y agregó que el hombre actuaba guiado por dos impulsos indestructibles (unverwüstliche Triebe) que eran: utilizar a los demás para su propio beneficio y su impulso de “poseer” (Eigentumstrieb) ${ }^{25}$. De allí la necesidad de crear instrumentos de regulación colectiva de la conducta humana para equilibrar los inevitables conflictos de intereses. Con Weber estaba de acuerdo en que todos los valores son de naturaleza relativa y que bajo ningún punto de vista, ni menos el de la ciencia, un valor podía erigirse como valor absoluto, pues los valores pertenecían a la esfera de la filosofía y las visiones del mundo. Este relativismo determinó su obra, y así lo expresó en “¿Qué es la justicia?” escrito en 1953:

“El hombre cree en la existencia de Dios, esto es, en la existencia de una justicia absoluta, pero es incapaz de comprenderla, es decir de puntualizarla conceptualmente. Quienes no aceptan esta solución metafísica del problema de la justicia pero se mantienen con la idea de los valores absolutos, en la esperanza de "poder” definirla racional y científicamente, se engañan a sí mismos con la ilusión de que es posible encontrar en la razón humana ciertos principios funda- 
mentales configuradores de esos valores absolutos, que en rigor, están compuestos por elementos emocionales de la conciencia.... La determinación de valores absolutos... de justicia... son fórmulas hueras mediante las cuales es posible justificar cualquier orden social”. ${ }^{26}$

La convicción sobre la imposibilidad de otorgar un significado objetivo a los distintos juicios de valor llevó a Kelsen a buscar un camino para crear un instrumento regulador de las conductas humanas a través de la ley. Por esta razón propuso su teoría del "derecho puro" que aceptando la diversidad de estos juicios, se concentrara en su regulación a través de normas cuya validez radicara en su proceso de formulación y no de contenido. El "derecho puro" surgió así como un ordenamiento jurídico autónomo e independiente de las otras áreas de la ciencia social como la sociología, la filosofía, la religión y otras.

Una norma procede de otra y existe una sola "norma fundamental" (Grundnorm) cuya validez se presupone y que rige para todo el edificio jurídico kelseniano ${ }^{27}$. Esto le entregaba la base para plantear la pureza metodológica de las normas libre de toda influencia ajena a su propia lógica de producción, vigencia y derogación. Otra idea pilar del "derecho puro" de Kelsen era su tajante oposición al dualismo entre derecho y Estado ya que no concebía al derecho más que al emanado del Estado. "El Estado de derecho kelseniano es un Estado regulado por el derecho y no un Estado vinculado por los derechos”28. Rechazaba la idea de contraponer el derecho público al privado, ya que sería una forma de desconocer la implicancia que tenía el Estado en el segundo.

Kelsen comprendía el "poder” estatal como “poder” jurídico o dicho de otra manera el Estado como parte constituyente del ordenamiento jurídico y no fuera de él. Es justamente en este punto donde protagonizó una dura polémica con la concepción sociológica del derecho de Max Weber pues éste planteaba que en la realidad existían varios ordenamientos normativos aparte del derecho estatal cuyas lógicas podían entrar en contradicción. Así por ejemplo, para Weber un “orden” era ‘convención': “...cuando su validez está garantizada por la probabilidad que dentro de un grupo de hombres una conducta tropiece con rechazo" y estaba convencido que las más severas sanciones las aplicaban los individuos a través de las ‘convenciones' y no a través del derecho. Un “orden” se transformaba en derecho, en cambio: "cuando está garantizado externamente por la probabilidad de la coacción física o psíquica ejercida por un cuadro de individuos que actúan para hacer cumplir ese orden o bien para castigar su transgresión”29.

Kelsen rechazaba esta idea, ya que para él no es la coerción física estatal aquella que garantizaba el orden, sino que exclusivamente el contenido de la acción social enunciado por las normas jurídicas que eran a su vez parte misma del Estado de derecho. La sanción era para él parte de la norma y no la garantía como lo planteaba $W_{e b e r}{ }^{30}$. En su tajante crítica contra aquellos que veían al Estado trascendiendo al derecho señalaba que 
esta concepción atribuiría al Estado un carácter “metajurídico” ubicándolo en el fondo en un espacio fuera de la regulación jurídica con lo cual adquiriría prácticamente una personalidad con ribetes de divinidad. Por eso para Kelsen:

"La teoría del derecho y de Estado es la misma. Es la teoría de la obligación del Estado hacia sí mismo y su autolimitación, en virtud de la cual el Estado suprajurídico, convertido en persona, se somete con plena voluntad a su propio orden jurídico que el mismo ha creado, y de "poder" extrajurídico se convierte sencillamente en un ser jurídico, el derecho.”31

La concepción del "derecho puro" en Kelsen como una "técnica social" o de "interpretación de los hechos sociales" lo llevó a plantear que para que éste pudiera realizarse se precisaba la tolerancia frente a la diversidad natural de los juicios de valor. Al ser la democracia el sistema político más adecuado, conocido hasta ahora, para dirimir conflictos aceptando la validez de las distintas opciones religiosas o políticas de los seres humanos $^{32}$, Kelsen se transformó en un defensor teórico y práctico de la democracia. En ella vio un sistema político dotado de dispositivos de protección de las minorías frente a las mayorías que era capaz de generar compromisos aceptables para las partes ${ }^{33}$.

En resumen el "hombre jurídico" que proponíamos al principio como prototipo de hombre moderno de Kelsen no puede pensarse fuera del contexto de la democracia ${ }^{34}$, pues es un sujeto capaz de aceptar las reglas del Estado de derecho en un contexto de pluralidad.

Los prototipos de Weber y Freud, el "hombre burocrático" y el "hombre neurótico” pasan ahora a ser regulados en la visión de Kelsen por un Estado que es idéntico al derecho y viceversa. Las reglas para el autocontrol racional de Weber y de reconquista de la salud mental del neurótico vienen a ser definidas exteriormente por el derecho y teóricamente están al alcance de todos por igual. El derecho concebido como proceso dinámico y democrático sin núcleos inamovibles se presenta como una solución colectiva frente a la solución individual y un tanto aristocratizante que proponían Weber y Freud: el autocontrol racional o la sanación mental mediante una psicoterapia personal.

\section{Poder, dominación y libido}

El concepto del "poder" ha tenido desde siempre un significado clave dentro de las ciencias sociales, ya que este fenómeno constituye el más importante mecanismo de selección del tipo de organización que se dan los seres humanos para vivir en sociedad. La tentación de definir el contenido del "poder" desde el mundo valórico es tan antiguo como el fenómeno mismo y las discusiones acerca de la validez de su ejercicio son hasta el día de hoy materia de luchas antagónicas irreconciliables en muchas partes del mundo. 
Si bien es cierto que las relaciones individuales están determinadas por vínculos de "poder", lo que nos interesa estudiar aquí es de qué manera éstas se expresan a nivel social y cuáles son las características del fenómeno del "poder" como hecho cultural en la sociedad moderna.

La discusión acerca del fenómeno del “poder” marcó fuertemente la obra de Weber, Freud y Kelsen. Se podría afirmar sin temor a equivocarse que casi todas las definiciones de "poder" que encontramos en los autores contemporáneos ${ }^{35}$ contienen los elementos que definieron estos tres pensadores clásicos, especialmente y en un lugar destacado, Weber.

Su definición del "poder” (Macht) como "relación social” (soziale Beziehung) y su estrecha relación con el concepto de "dominación” (Herrschaft) y las "fuentes de legitimación" contribuyeron a delimitar este fenómeno tanto en su esencia estructural como en sus formas históricas de existencia.

Weber distinguía entre “poder” (Macht) y “dominación” (Herrschaft) trazando de este modo una diferencia que ha sido clave para entender el tipo de "poder" que detenta el Estado moderno occidental. Mientras definía el "poder" como la "probabilidad de imponer la propia voluntad dentro de una relación social aún contra toda resistencia y cualquiera que sea el fundamento de la probabilidad", la "dominación" era "la probabilidad de encontrar obediencia dentro de un grupo determinado para mandatos de toda clase o específicos"36. La "dominación" era una forma "eficaz" de "poder”, donde existía la voluntad de la obediencia y la creencia en la legitimidad del "poder". Con ello sentaba las bases para comprender el fenómeno del "poder" más allá de sus contenidos específicos poniendo el acento en sus mecanismos (monopolio legítimo de la violencia por parte del Estado) y en la disposición de la conducta humana, donde encontramos tanto la obediencia, la disposición de mandar, la admiración, los afectos, el carisma, el temor, la sumisión, el sometimiento y la resistencia que fueron a su vez investigados por Freud e incorporados a la reflexión jurídica por Kelsen.

Recordemos que el abordaje de Weber de los fenómenos sociales era de tipo descriptivo explicativo y no valórico. Lo que a él le interesaba era comprender la evolución de una acción social partiendo por entender desde la intención subjetiva del que la realiza hasta conocer los medios que elige para conseguir su propósito y si los logra efectivamente tal cual los pensó. Weber presuponía en la sociedad moderna occidental una intencionalidad sobre la base de la "razón instrumental" con lo que dejaba fuera de su análisis aquellos elementos aleatorios e irracionales de la conducta humana.

Esencial en las investigaciones weberianas sobre la especificidad del capitalismo moderno occidental es la tesis de la predominancia de la "racionalidad instrumental" (Zweckrationalität) por sobre los otros "tipos ideales" de racionalidad que son la "racionalidad según los valores" 
(Wertrationalität), la "racionalidad según los afectos" (afektuelle Rationalität) y la "racionalidad según la tradición” (traditionale Rationalität) cuya predominancia se da en etapas anteriores al surgimiento del capitalismo moderno y responde más bien a formas de gobierno basadas en el "poder" de los jefes de tribu, de los monarcas, de los señores feudales, caudillos o magos.

La singularidad de la "racionalidad instrumental" se fundamenta en una secuencia lógica del accionar social que comprende tres pasos: ponerse un objetivo, elegir los medios óptimos para lograrlos según los valores que se reconocen como válidos y ser capaz de medir las consecuencias de la acción. Se trata de un tipo de acción social "responsable" y "coherente" orientada hacia el logro efectivo de las metas. Así el desarrollo de la ciencia y la tecnología juega un rol principal dentro del sistema económico que persigue la acumulación de riquezas y de valores asociados a ella, ya que nada se deja al azar o a lo que las circunstancias dicten. De la misma manera, el Estado busca una administración profesionalizada y tecnificada a través de la burocracia moderna atenida a las leyes, al decreto y al conocimiento, siendo la meritocracia una piedra angular para la selección adecuada de su personal. Como ya hemos mencionado, el Estado moderno se define por el medio que utiliza para gobernar que es el monopolio legítimo y exclusivo de la coerción física.

En comparación con los otros tipos de racionalidad descritas por Weber, la secuencia lógica de la acción subyacente a la "racionalidad según los valores" no incorporaba la responsabilidad por las consecuencias de la acción, pues lo central aquí era servir a los principios. Algo similar sucede con la "racionalidad afectiva" que sólo se fija metas eligiendo los medios sin importar ni los valores ni los efectos de la acción, porque lo que prima en esta lógica son los sentimientos en las acciones sociales. Por último, el tipo de "racionalidad tradicional" rompe con la secuencia lógica de la "racionalidad instrumental" concentrándose únicamente en su fin que es conservar la tradición, sin importar ningún otro criterio: ni los medios, ni los valores, ni los efectos de la acción social.

Importante es subrayar el aspecto de la "predominancia" de un tipo de racionalidad, ya que en la realidad de la sociedad moderna occidental estos "tipos ideales" de racionalidad planteados por Weber se dan en forma combinada pero siempre bajo el predominio de la "racionalidad instrumental". Sin este desarrollo habría sido imposible el surgimiento de sociedades como las occidentales con un "estilo racional de vida” (rationale Lebensführung) en todos sus ámbitos: En la religión con la superación del politeísmo, en el derecho con una jurisprudencia de lógica única y formal, en la economía con un sistema productivo basado en la ciencia y la técnica con el fin de aumentar la riqueza, en la administración pública con un aparato burocrático legal y en la política con un sistema de dominación profesionalizado y basado en una estructura de partidos políticos regulados por la ley capaz, a su vez, de dirimir conflictos de intereses. Esta constelación de factores habría hecho posi- 
ble el surgimiento de las sociedades occidentales más avanzadas.

Vale la pena recordar que Weber se limitaba sólo a describir y comprender la evolución de estos procesos y nunca a calificarlos como una forma "superior" o "mejor" de sociedad. Lo relevante era la eficacia y eficiencia con la que se había logrado manejar los problemas de las sociedades de un mayor nivel de complejidad basándose en la "racionalidad instrumental" y no en el diletantismo muy propio de los otros tipos de racionalidad. Weber, sin embargo, estaba consciente sobre las consecuencias de este estilo de vida, pues afirmaba que aún con los progresos técnicos, el ser humano, no era capaz de dar respuesta a las preguntas existenciales sobre el sentido de su vida, tal cual lo había planteado Leo Tolstoi en su libro de 1886 sobre “¿Qué hacer con nuestra vida? ${ }^{37}$

Las investigaciones psicoanalíticas realizadas por Freud complementaban este abordaje weberiano a través de lo que él denominaba "alma colectiva", pues ésta surgía esencialmente desde las esferas del inconsciente de la conducta humana y generaba relaciones de "poder" inclasificables dentro de la lógica de la sociología comprensiva de Weber.

Apoyándose en las investigaciones psicoanalíticas de Le Bon ${ }^{38}$ sobre la "masa psicológica", afirmó que la multitud se tornaba en una especie de ser colectivo con "alma propia" y conductas comunes basadas en el inconsciente: el sentimiento de omnipotencia que no lo tendría como individuo, la irresponsabilidad basándose en el anonimato, la liberación de la represión de las tendencias del subconsciente individual, el contagio mental de las ideas, sugestibilidad y neutralización de la conciencia. Le Bon planteaba que el hombre integrado a la masa hacía una regresión a su estado primitivo:

"Por el sólo hecho de formar parte de una multitud, desciende varios escalones en la escala de la civilización. Aislado, era quizás un individuo culto; en multitud es un instintivo, y por consiguiente un bárbaro. Tiene la espontaneidad, la ferocidad y también los entusiasmos y los heroísmos de los seres primitivos.... la multitud es tan autoritaria como intolerante. Lo que la multitud exige de sus héroes es la fuerza e incluso la violencia. Quiere ser dominada, subyugada y temer a su amo... y (tiene) un ... horror inconsciente a las novedades susceptibles de modificar sus condiciones de existencia" ${ }^{39}$.

Más adelante anotaba que la masa tendía a las conductas neuróticas porque las "multitudes no han conocido jamás la sed de la verdad. Demandan ilusiones a las cuales no pueden renunciar. Dan siempre la preferencia a lo irreal sobre lo real, y lo irreal actúa sobre ellas con la misma fuerza que lo real”.

Para Freud este predominio de la vida imaginativa y de la ilusión sustentada por deseos insatisfechos era el rasgo característico de la psicología de las neurosis ${ }^{40}$. A pesar que Le Bon había realizado una asertiva 
descripción de las conductas de las masas, Freud no se contentó con ello y se planteó la pregunta acerca de cuál era el "poder” que mantenía vinculados a los individuos en una masa. Su respuesta fue que en el "alma colectiva” también había "relaciones amorosas" o "lazos afectivos" que actuaban como vínculo de "poder" entre los individuos. A este tipo de amor lo llamó "libido" como una versión amplificada del amor derivado del instinto del Eros. La libido actuaría como una necesidad del individuo integrado a la masa de estar de acuerdo con los otros y no en oposición a ellos por "amor a los demás”.

Esta hipótesis permite comprender los fenómenos de la sumisión, obediencia y autoridad, constitutivos de las relaciones de "poder" como resultado de la "libido", entendida como una energía que abarca una variada gama de instintos relacionados con el amor más allá de la cópula sexual: El amor paterno, el filial, el amor a sí mismo, la amistad, el amor a la humanidad en general y a objetos concretos o ideas abstractas.

Contrastando esta conclusión con el concepto weberiano de los "tipos puros de dominación legítima” (reine Typen legitimer Herrschaft) que eran el "racional burocrático", el "tradicional” y el "carismático", encontramos que los elementos freudianos que unen a la masa a través de la libido, cumplen también en estas definiciones roles similares, ya que en estos tres tipos de dominación es el vínculo a una creencia o a un líder ( ya sea burocrático, carismático o tradicional) lo que determina la actitud de los individuos entre sí como parte de una masa. La "estructura libidinal” de la masa se construiría, pensando con Weber sobre la base de la creencia en la legitimidad de una autoridad legal, en la santidad de las tradiciones o bien en la confianza en una persona de ejemplaridad extracotidiana. Esto es obviamente lo que Freud definía como la necesidad que tenían los individuos de identificarse con los otros a través de lazos afectivos propios de la libido.

Al plantear Weber los “tipos ideales” como categorías analíticas para sus investigaciones, aclaró que éstos nunca se daban en la realidad en su forma pura, sino que más bien como híbridos que contenían elementos de varios "tipos ideales”. Recogiendo esta idea podría plantearse que las relaciones de "poder" entre los individuos dentro de una masa están determinadas por factores racionales instrumentales, que según Weber son los predominantes en la sociedad moderna occidental, y factores derivados del subconsciente que son irracionales. Si esta reflexión fuera válida, resultaría lógico plantear que la predictibilidad de los distintos escenarios de "poder” o dominación entre los seres humanos estarán siempre sujetos a un alto grado de incertidumbre.

Tanto Weber como Freud estudiaron los mecanismos constituyentes de las distintas relaciones sociales entre ellas las de "poder" y los factores determinantes de su evolución en distintos planos. Freud pensaba desde el psicoanálisis que los fenómenos de dominación eran la resultante de conductas gatilladas principalmente por el subconsciente y sus pulsaciones in- 
natas en los seres humanos: Eros e instinto de muerte. Weber, desde la sociología comprensiva, pensaba que las cuestiones inherentes al "poder" en la sociedad moderna occidental habían logrado ser manejadas predominantemente desde una lógica de racionalidad instrumental, pero no dejó de creer que incluso la democracia con un aparato burocrático profesionalizado necesitaba de una personalidad "carismática" so pena de enfrentarse a un sistema político sin líder y con ello a la “dominación de las camarillas” sin vocación política. El tipo de democracia sin líder provocaría según Weber el "vaciamiento espiritual" (Entseelung) y la "proletarización intelectual" (geistige Proletarisierung) ${ }^{41}$ en los seguidores de los partidos.

Como ya habíamos mencionado anteriormente, Hans Kelsen conocía estas investigaciones con lo que se podía adelantar a los devastadores efectos que tendría una regresión de las masas hacia la "horda primitiva" o bien de una administración autoritaria y desequilibrada del "poder" a la hora de dirimir conflictos de intereses respetando el derecho de las partes. Kelsen planteó, que la "normatividad es una exigencia racional frente a la violencia natural del hombre" ${ }^{42}$.

El tema de la regulación del "poder” a través de la figura del Estado moderno fue una pieza esencial en las reflexiones de Weber, Freud y Kelsen.

\section{Poder, Estado y Derecho.}

Weber definió al Estado como una "relación de dominación (Herrschaftsverhältnis) de hombres sobre hombres basada en el medio de la violencia legítima" ${ }^{33}$. Para él la especificidad del Estado se definía por el medio y no por sus fines, que era el monopolio de la violencia legítima. Para que existiera el Estado los dominados tenían que someterse a la autoridad a la que aspiraban los que dominaban. El "Estado moderno", como un fenómeno específico del occidente, adoptaría características propias transformándose en:

“... una asociación de dominación de carácter institucional, que ha intentado, con éxito, monopolizar la violencia física legítima dentro de un territorio como medio de dominación y que, para este fin, ha reunido todos los medios materiales de funcionamiento en manos de sus dirigentes, pero expropiando a todos los funcionarios estamentales que antes disponían de estos medios por derecho propio y poniendo a sus propios dirigentes en la cúspide en vez de aquellos”44.

Partiendo de estas definiciones, Weber identificó la "política” como un conjunto de relaciones sociales determinadas por la "aspiración a participar en el "poder" o a influir en la distribución del "poder" entre distintos Estados o, dentro de un Estado, entre los distintos grupos humanos que éste comprende" ${ }^{45}$.

$\mathrm{Al}$ leer detenidamente estas definiciones, vemos que Weber se refería al hombre en política siempre como un hombre organizado en el entramaje 
de relaciones de "poder" en la lucha por la conquista del Estado, institución política central en la sociedad moderna que regula en general las reglas de la distribución del "poder”. Al ser el Estado moderno un ente regulador por poseer en última instancia el monopolio de la coerción física, su relación con el "derecho formal" se hacía evidente porque creaba "normas" que debían ser obedecidas por todos aquellos que pertenecían a su esfera de "dominación". Para Weber el derecho moderno era una "esfera propia de valor" (eigenständige Wertsphäre) con reglas abstractas dentro de una lógica racional formal. Desde ese punto de vista llegó a la conclusión que el Estado era un “ordenamiento jurídico” (Rechtsordnung).

Hasta aquí concordaba con Kelsen en cuanto a que la sociedad moderna había desarrollado una concepción del derecho positivo como necesidad reguladora del "ordenamiento vital" (Lebensordnung) y el mismo Kelsen reconocía esta concepción como un aporte fundamental de Weber a la teoría del derecho y el Estado. Sin embargo, Weber como sociólogo y Kelsen como jurista, se diferenciaron en sus teorías del Estado, ya que el primero la basó en las teorías del "poder” y el segundo en las teorías del derecho.

Los efectos de estos abordajes consistieron en que Weber diferenció entre "validez empírica" de la norma y la "validez ideal” o jurídica, mientras que Kelsen dio supremacía sólo a esta última pues, según su concepción, la norma era siempre producto de un sistema jurídico puro de lógica unitaria libre de conflictos y válido para todos.

Como mencionamos en el primer capítulo, para Kelsen el Estado moderno era el derecho y viceversa, ya que el mismo Estado y sus funciones eran reguladas por el derecho y a la vez eran parte de él. La consecuencia lógica de esta concepción era que el monopolio de la coacción física en manos estatales pasaba a ser regulada también por el derecho a diferencia de los regímenes autocráticos.

Para Weber el Estado requería de un aparato administrativo (Verwaltungsstab) que por medio de la coacción física hiciera valer el derecho con lo que quedaban en mutua dependencia. No obstante, Weber veía que en la realidad empírica la validez de las normas no sólo respondían al ordenamiento jurídico, sino que a múltiples situaciones, entre las cuales nombraba: la posibilidad que se respete la norma como válida por hábito o por miedo a la sanción social; O bien porque los sujetos solamente se “orientan por la norma” al actuar en sociedad o también están aquellos que se uniforman a la norma sin estar de acuerdo y los que desobedecen pero tienen presente la norma ${ }^{46}$. Kelsen contraplanteó que la sociología del derecho no podía investigar los comportamientos jurídicos de una sociedad, si no poseía un criterio que le permitiera distinguir un comportamiento jurídico de otro que no lo fuese. Por ello la sociología del derecho "dependía” de todas maneras de la ciencia del derecho.

A pesar de estas diferencias entre Kelsen y Weber, los dos coinci- 
dían que el Estado era un ordenamiento jurídico y que su especificidad era la coacción física. Lo importante es que el avance del derecho positivo marcó una diferencia cada vez más grande entre el derecho como ciencia de las normas aparte de la moral y la política permitiendo regular al Estado desde el punto de vista del derecho. De esta manera se encontró una vía para evitar que el Estado erigiera sus razones como las "objetivamente" superiores a otras auto-otorgándose el derecho de representar la "voluntad colectiva”, que Kelsen calificó como una ficción no comprobable empíricamente.

Lo indudablemente válido hasta el día de hoy del pensamiento de Weber es el haber planteado que el origen y estructura de la obediencia frente a los ordenamientos normativos era tan compleja que el ordenamiento jurídico, aunque así se lo propusiera, aún en su forma más avanzada como derecho positivo altamente profesionalizado y tecnificado, no podía regularla por sí solo.

Haciendo honor a esa complejidad, Kelsen incorporó las teorías de Freud a la conformación de su visión de la esencia psicológica e instintiva del hombre, como lo describimos en el capítulo 1.2.3. Siendo el hombre civilizado un ser que no sólo buscaba la felicidad individual, sino que también la de la comunidad, era inevitable el fenómeno de la aparición de las masas. En este contexto Kelsen investigó si el Estado moderno podía ser analizado bajo la categoría freudiana de "masa psicológica" con el fin de establecer si ciertas conductas en la conformación de masas se repetirían también en el Estado y cuál era el tipo de conducción estatal de las masas.

Como ya lo había estudiado Freud apoyándose en investigaciones anteriores ${ }^{47}$, la conducta de los individuos dentro de una masa dependía del tipo de "dirección" o liderazgo que tuvieran en esa masa y no del tipo de masa (efímera, estable o altamente organizada) a la que pertenecían. La hipótesis que la "masa organizada" neutralizaría los efectos negativos de la "masa primitiva" no le bastaba a Freud para entender el hecho fundamental de la psicología de masas que era "la carencia de libertad del individuo integrado en una multitud" con su consiguiente "disminución de la actividad intelectual”.

En términos de las relaciones de "poder", el hombre integrado a la masa podía ser fácil presa de manipulación, sometimiento y dominación al reemplazar el ideal del yo con el del "padre de la masa" pues renunciaba a la identidad individual. Ejemplos de estos procesos eran la Iglesia y el Ejército, ambas denominadas por Freud como "masas artificiales", duraderas y altamente organizadas. ${ }^{48}$ Tanto en el Ejército como en la Iglesia sus miembros tenían la ilusión de la presencia de un jefe, visible o invisible (Cristo o el jefe del ejército) que los amaba a todos por igual y ello era lo que cohesionaba a estas masas mediante los mecanismos psicológicos de la sugestión recíproca y de la identificación. Sin embargo, nadie podía ser igual a ese jefe que se sentía superior llegando a asemejarse al padre de la "horda primitiva”. Así surgía la figura del "jefe autoritario”. 
En este contexto, Freud no hablaba tanto del hombre como un "animal gregario" 49 , sino como un "animal de horda" 50 pues era más preciso a la hora de comprender la estructura de la "masa" conducida por un "caudillo".

El control de los impulsos innatos de la naturaleza humana fue visto por Freud como condición fundamental para el desarrollo de la cultura, especialmente el manejo de la agresividad para la convivencia civilizada. Este manejo consistía en la prohibición de vivir los impulsos sexuales libremente enmarcándolos en un tipo de sexualidad negadora del placer y limitada a la reproducción del matrimonio monógamo, y por otro lado en la obligación de reprimir su natural agresión por la imposición cultural de dar predominancia al amor, o Eros.

Freud destacó el carácter autoritario del hombre civilizado al no bastarle con reprimirse a sí mismo cuando se subordinaba al orden cultural. La severidad de su "conciencia moral” iba en aumento y exigía al mismo tiempo que los "otros" también se doblegaran y reprimieran sus impulsos gatillando una presión civilizatoria colectiva.

Estos mecanismos los analizó en "El Malestar de la Cultura" (1929) y nos señaló que , a pesar de ellos, el sentido de vida del ser humano consistía en buscar la felicidad ( o placer), mientras que la cultura perseguía el objetivo de frenar, manejar o moderar los instintos primarios del hombre.

El conflicto entre individuo y masa es la llave para entender el fenómeno del "malestar" cultural en occidente e identificar el tipo de relaciones de "poder" que se establecen en su curso. Al diferenciar los distintos tipos de masa según su tipo de conducción, Freud postuló que su destino residiría en la voluntad civilizatoria de su conductor, con lo que le otorgó suma importancia a los líderes y una extrema fragilidad a la multitud en manos de conductores autoritarios que las llevaran a procesos de "regresión" hacia la "horda primitiva" con todos los efectos negativos: la interacción entre agresión, sumisión, represión y obediencia.

Si el Estado actuara teóricamente como una idea conductora de las “masas” y las guiara equilibradamente para manejar las perturbaciones inevitables de la vida colectiva derivadas del instinto de destrucción y de autodestrucción, entonces los colectivos podrían construir un destino cultural con preponderancia del Eros.

Kelsen compartió con Freud sus investigaciones acerca del carácter de las masas y vio en el surgimiento de esta alma colectiva los mismos peligros de regresión primitiva de los seres humanos. No obstante, Kelsen concluyó que el Estado moderno no podía ser visto como un fenómeno de psicología de masas, aún reconociendo que el proceso psíquico en que se operaba la construcción de la masa sin conductor era análogo a la construcción de la nación, religión o Estado. 
Para Kelsen el Estado era: “Una idea-fuerza, una ideología que los individuos integrantes de la masa pusieron en lugar del Yo ideal para "poder" identificarse entre sí" 51 . No olvidemos que para este jurista el Estado era el derecho, de tal manera que podría afirmarse que los integrantes de la masa renunciarían al caudillo o jefe de la horda en el sentido freudiano para poner en su lugar al derecho como regulador de sus vidas. La condición para la formación de este Estado era para Kelsen la existencia de la democracia, único sistema capaz de la tolerancia en cuanto a la diversidad de ideas. Aquí, Kelsen observó que el Estado concebido como un contenido específico de sentido para la actuación humana o -dicho de otra manera- como sistema autónomo de normas jurídicas para regular el comportamiento humano, aportaba un elemento civilizatorio a la sociedad ya que eran los mismos individuos aquellos que elegían por voluntad el mecanismo de organización social que los hacía identificarse el uno con el otro bajo un Estado de derecho. Al poner al derecho en lugar del "padre" de la masa, se rompía la omnipotencia de su autoridad permitiendo al individuo romper con los mitos del Estado como un "ser vital hiperbiológico" análogo al concepto de Dios $^{52}$.

Desde su punto de vista, la cuestión del Estado en la sociedad moderna dependía de dos factores: uno que el Estado mismo sea el derecho y otro que el derecho pueda aplicarse en un marco de tolerancia frente a la diversidad de valores con normas claramente dispuestas en cuanto a su generación y procedimiento. Las implicancias que se derivaban de esta posición eran, por un lado, que al igualar el Estado al derecho no quedaba ninguna área normativa fuera de la influencia del Estado y con ello el Estado se aseguraba el monopolio de la coerción física como último medio de regulación de las conductas de los seres humanos. Por otro lado, al reconocer la relatividad de los valores, Kelsen planteaba que el Estado debía desempeñarse en un ambiente de tolerancia, que sólo la democracia podía garantizar. Al formular la teoría del "derecho puro", se pone al derecho y al Estado en una posición de árbitro regulador, pero sin poderes absolutos en el sentido de su superioridad. Esto es, el Estado democrático por estar inserto dentro de una sociedad de múltiples valores representados por las organizaciones sociales y partidos políticos, debe velar por encontrar soluciones a los conflictos de intereses, aplicando el criterio de la mayoría, pero protegiendo a las minorías de posibles arbitrariedades por parte de la primera.

La propuesta kelseniana de crear Tribunales Constitucionales como cuerpo de jueces independientes del "poder" judicial para velar por la pureza en la aplicación de las leyes por parte del Estado a pedido del parlamento o bien de otras instancias gubernamentales, constituyó una expresión de su convicción acerca de que tampoco el Estado podía estar libre de todo tipo de controles. En su libro "Esencia y Valor de la Democracia" (1919) ya había planteado la relación contradictoria entre la libertad y la igualdad de los hombres como instintos primarios y al mismo tiempo su necesidad de vivir en sociedad requiriendo de una organización del "po- 
der" colectivo que inevitablemente conducía a restringir la libertad de los individuos. Por esta razón siempre habría un conflicto entre la voluntad individual y el orden social y de allí la urgencia de "normar" para evitar que estos conflictos derivaran en estados de agresión y hostilidad de unos contra otros.

En este contexto Kelsen era enemigo del fuerte presidencialismo en algunas constituciones, ya que para él esta característica era más bien cercana a la autocracia que a la democracia.

Kelsen tuvo una gran influencia en la modernización del derecho a nivel mundial, pero especialmente en Europa. Su experiencia con el nazismo, lo llevó a reflexionar sobre la necesidad de legislar en democracia y en cómo perfeccionar esta "técnica de organización social”, para crear ordenamientos jurídicos por sobre las ideologías y que fueran altamente dinámicos y sin cuerpos inmodificables.

Pareciera ser que para el "hombre jurídico", prototipo de hombre que proponíamos para Kelsen, el origen de la "autoridad" que lo rige se torna transparente y susceptible de mejorar permanentemente en beneficio propio. Esto no significa que con la aparición de este tipo de "Estado moderno", la esencia natural del ser humano descrita en los capítulos anteriores, fuera posible de cambiar, sino que solamente de regular con la racionalidad de las normas derivadas del derecho positivo en un ámbito de tolerancia.

En resumen, podría decirse que la cuestión del “poder” como fenómeno social, psicológico y jurídico fue abordado por nuestros tres autores desde las raíces mismas de la esencia de la naturaleza humana para contextualizarlo en sus modelos de análisis. No es casualidad que tanto Weber como Freud y Kelsen estudiaran con mucho detalle la relación que existía entre creencias religiosas y formas de organización social a través de la historia para determinar el rol que cumplían los valores y creencias en la conformación del tipo de sociedad en que vivían los hombres. Justamente el derecho y el Estado como plataformas de distribución y regulación del "poder" no podían ser solamente comprendidos como estructuras institucionales con personalidad propia porque ellos eran productos del accionar humano y por ello susceptibles de cambiar. La condición para ello era el individuo equilibrado psicológicamente.

El Estado visto como masa psicológica guiada por un caudillo o idea abstracta de Freud le permitió comprender su estructura libidinosa y los mecanismos de sometimiento de las masas frente al líder, pudiendo identificar los peligros que se derivan de la conformación del alma colectiva que no es más que la anulación del alma individual y la responsabilidad ante sus actos. Tanto Freud como Kelsen alcanzaron a vivenciar la expresión máxima de lo que ellos mismos habían descrito en sus obras sobre la regresión primitiva de las masas con el advenimiento del régimen nazi en Alemania. 
La concepción del Estado de Weber como autoridad político-burocrática funcional a la economía y asociación de dominación contribuyó al análisis crítico de los efectos negativos que tendría sobre la sociedad la “dominación burocrática” o el gobierno de las “máquinas partidarias”, proponiendo modelos de políticos equilibrados que respondieran a su conciencia y tuvieran responsabilidad sobre sus propias decisiones más allá de las pasiones ideológicas.

Las reflexiones de Kelsen sobre el Estado moderno democrático como parte del derecho hicieron un aporte fundamental para entender la necesidad de superar la idea del Estado "metajurídico", ya que esta concepción se había prestado para posicionar al Estado como un ser ubicado por sobre la ley abriendo las puertas para todo tipo de arbitrariedades. La idea del Estado subordinado al derecho y con ello a la voluntad de los hombres, contribuyó a desmistificar la idea de su "omnipotencia jurídica" como una fuerza sobrenatural para ubicarlo definitivamente como un producto de la acción humana ${ }^{53}$.

\section{El poder, a la luz del "nuevo paradigma científico"}

En el marco de las investigaciones acerca de las nuevas formas de organización del "poder" (en redes) derivadas de la era de las comunicaciones y alta interconectividad mundial, se ha llegado a plantear que las relaciones de "poder" han vivido una especie de transformación radical al cambiar la estructura de generación, distribución y utilización de la influencia de los actores de una "red". A pesar de que existen muchas definiciones del concepto de "red", éste se comprende fundamentalmente como una heterogeneidad de nodos que se conectan en forma aleatoria con los otros elementos en función de un fin colectivo común. Lo importante es la cantidad de conexiones que logre establecer la red en torno a su fin. Estas conexiones son impredictibles, interconectadas, autoreguladas, no jerárquicas y abiertas $^{54}$.

En esta misma línea se ha propuesto incluso que desde el punto de vista de la sociología jurídica el Estado debiera verse como cualquiera otra estructura organizacional normativa dentro de la institucionalidad de una sociedad ${ }^{55}$, pues la administración del "poder" antes concentrada en el Estado estaría crecientemente teniendo lugar en estructuras descentralizadas.

Estrechamente vinculado a estas posturas se encuentra el análisis sobre la cuestión del "poder" en torno a las nuevas formas de investigación derivadas del "cambio de paradigma científico". Cuando hablamos del "nuevo paradigma científico", nos referimos a un modelo de ciencia basado fundamentalmente en los descubrimientos provenientes de la física teórica a partir de la teoría de la relatividad desarrollada por Albert Einstein ${ }^{56}$, quien fuera premio Nobel de física en 1925, y el "principio de la incertidumbre” elaborado por Werner Heisenberg ${ }^{57}$ entre 1925 y 1926, que más 
tarde sería una de las formulaciones básicas de la mecánica cuántica matricial que le valdría el premio nobel de física en 1932.

Estas teorías causaron una verdadera revolución en la ciencia dando lugar al reemplazo del paradigma científico mecánico o determinista de Newton válido hasta ese momento. En el campo de las ciencias sociales también tuvo repercusiones. Paulatinamente se empezó a investigar la especificidad de los tipos de organización que se daba el ser humano para la vida en sociedad desde puntos de vista multidimensionales y también se abordaron críticamente preguntas sobre el origen del universo y su vínculo con el ser humano. Asimismo se estudió el significado de las percepciones que un individuo tenía de la realidad en cuanto a espacio, tiempo y movimiento como parte de una unidad y no como procesos separados. Ejemplos de ello son la teoría de las redes sociales, del caos y de los "sistemas adaptativos complejos” (SAC) ${ }^{58}$ que vendrán a enriquecer la discusión acerca de las nuevas estructuras organizacionales que adopta el fenómeno del "poder", especialmente en la era del internet con su infinito potencial de intercomunicación global.

Cuando Werner Heisenberg ganó el Premio Nobel de Física en 1932 se refirió a los efectos que tendrían sus investigaciones acerca del "principio de incertidumbre" sobre el acercamiento entre las ciencias naturales y las ciencias sociales que hasta ese momento se habían practicado separadamente:

"El rasgo característico del desarrollo que se aproxima será precisamente la unificación de la ciencia, la superación de los límites que han ido surgiendo a lo largo de la historia entre las distintas disciplinas unitarias" ${ }^{\prime 9}$.

Esta afirmación es altamente interesante desde el punto de vista de la retroalimentación entre ciencia natural y social, pues ésta podría contribuir a entender el comportamiento de los seres humanos a partir de otro tipo de abordaje.

El concepto de tiempo cambió fundamentalmente con la teoría de la relatividad de Einstein reemplazándose la concepción lineal del mismo por una que se expandía o se contraía dependiendo de la ubicación de las personas en el universo. Sin embargo, Einstein nunca aceptó que en las leyes de la física existiesen elementos aleatorios o impredictibles. Fue Heisenberg con su nueva imagen de la realidad llamada mecánica cuántica que descubrió a través de sus investigaciones que "las partículas pequeñas ya no tenían una posición y una velocidad bien definidas, sino que cuanto mayor fuera la precisión con que se determinara su posición, menor sería la precisión con que podríamos determinar su velocidad y viceversa" ${ }^{60}$. Su "principio de incertidumbre" descartaba la posibilidad de la exactitud del conocimiento destronando la ley de "causa y efecto" propio de la filosofía determinista del universo. Ahora se hacía necesario abordar la generación del conocimiento a partir del mundo de las probabilidades. 
Luego de Heisenberg, muchos otros científicos han enriquecido e innovado estas ideas ${ }^{61}$, pero lo central sigue siendo que la impredictibilidad de la realidad física ha dado lugar a la formación de un "nuevo paradigma científico” que también es atingente a las ciencias sociales.

¿Pero qué tiene que ver nuestra revisión crítica sobre los conceptos del "poder" y la naturaleza del ser humano subyacentes al pensamiento de Weber, Freud y Kelsen con estas divagaciones sobre el "nuevo paradigma científico"?

La respuesta gira en torno a las interrogantes que surgen sobre quién tiene realmente hoy el "poder” en la sociedad, cómo se distribuye y de qué modo se ejerce en un mundo global con altos niveles de velocidad, de difusión y de acceso a la información a través de internet y sus redes sociales como, por ejemplo, Twitter y Facebook. Otra pregunta se plantea acerca del carácter que tendría el Estado, como representación central y tradicional del "poder" en las teorías clásicas y por consiguiente si el derecho concebido como lo hacía Kelsen, sigue jugando el mismo rol en este nuevo escenario. No puede dejar de considerarse tampoco el complejo de preguntas acerca de los efectos que tendrían estas nuevas formas de organización en redes sobre la naturaleza psicológica del ser humano investigada por Freud y por supuesto si la administración del "poder” a través de la burocracia profesionalizada, tal cual la describió Weber logrará mantener la "eficacia” en este nuevo escenario.

Indudablemente el estudio de estas materias sobrepasaría el marco y la intención de un breve ensayo como éste, pero al menos abordaremos algunos de estos temas con el fin de estimular la reflexión sobre ellos.

Antes de la crisis financiera mundial del 2008, cuyo epicentro estalló en Estados Unidos, las teorías acerca del debilitamiento del concepto del "Estado tradicional” (jerárquico, autoritario, centralizado, burocrático y basado en la sanción y el temor) parecían ganar validez al momento de plantear que este tipo de Estado pertenecía a la era industrial con su sociedad de masas y no podía responder a las exigencias de la era de las comunicaciones. Se hablaba del surgimiento de un tipo de organización social flexible y abierto que requería de otro tipo de ejercicio del "poder" cuyas características principales serían la descentralización, el estímulo, la facilitación, la negociación, la persuasión o la empatía ${ }^{62}$. Al mismo tiempo, ya desde fines de los años setenta se venía impulsando en Europa y Estados Unidos un radical proceso de modernización del Estado ${ }^{63}$ para hacer frente a los nuevos desafíos en la administración pública en materia de eficiencia y eficacia y del uso de las nuevas tecnologías de información y gobierno electrónico.

La modernización del Estado buscaba mejorar las deficiencias de los sistemas de administración tradicional introduciendo técnicas de planificación por resultados, de agilización de la gestión pública y políticas de ascenso profesional acompañados de remuneraciones según rendimiento. 
La así denominada "Nueva Gestión Pública” (NGP) se transformó en una de las bases teóricas para apoyar procesos de modernización del Estado a nivel mundial ${ }^{64}$. Conceptos como el "benchmarking"65, la "accountability", o la "gestión por resultados" se hicieron familiares en los círculos de la administración pública y parecían cambiar el carácter centralizado y vertical en los asuntos de gobierno dando lugar a acelerados procesos de desconcentración y descentralización de responsabilidades de gestión.

Después de la crisis financiera producida principalmente a través de la red financiera internacional con una velocidad y profundidad nunca antes vista, se volvió a establecer en toda su amplitud la centralización de las decisiones del Estado como institución reguladora principal dentro de los más altos círculos de "poder" y prácticamente a puertas cerradas, ya que los parlamentos debían aprobar o rechazar las propuestas elaboradas por especialistas económicos a velocidades que prácticamente no les daban tiempo ni siquiera de comprender en toda su magnitud las medidas que estaban aprobando. La existencia de las nuevas formas del "poder" descritas en la literatura especializada y los resultados positivos registrados en el curso de las reformas del Estado no fueron suficientes para prever los efectos de la crisis y hacerles frente con nuevos instrumentos.

Esta experiencia demostró de qué manera una organización en redes, como era el mercado financiero internacional, con sus múltiples actores y conexiones, con su flexibilidad y dinamismo y sus formas descentralizadas y abiertas de funcionamiento comenzó a generar patrones de conducta configurándose en la práctica un "poder” paralelo al Estado y al derecho. Los mecanismos de autocontrol y autoequilibrio que se le atribuían a estos sistemas de redes se desbordaron de un momento a otro y la deficiente regulación estatal causaron la ruina económica de millones de personas y países completos con consecuencias fatales para el control de los impulsos de hostilidad y abusos entre seres humanos. Baste recordar los millonarios bonos que se hicieron pagar los brokers, agentes de la crisis, a pesar de la bancarrota de millones de clientes que les habían confiado sus ahorros y habían quedado para siempre en la pobreza.

La evidencia empírica generó nuevas interrogantes en materia de qué tipo de gestión tendría que seguirse para evitar situaciones como la crisis financiera del 2008 y de qué manera debía corregirse o complementarse el proceso de modernización de las gestiones públicas internacionales. Interesante resultaría una reflexión acerca de las nuevas expresiones del ejercicio del "poder" en conexión con el pensamiento clásico moderno, pues allí podríamos encontrar orientaciones para dilucidar si las nuevas formas del "poder" tienen la capacidad efectiva de reemplazar las relaciones descritas por Weber, Freud y Kelsen o bien cuál sería su punto de encuentro o de equilibrio. El "nuevo" concepto del "poder", deberá sin lugar a dudas ser repensado en la perspectiva de su relación con el Estado, tal cual lo había predicho Hans Kelsen: el Estado democrático en su identificación con el derecho moderno como principal mecanismo regulador de todas las conductas humanas. 
Desde un punto de vista weberiano, se comprobó que la crisis financiera no podría haber sido manejada sin la presencia de equipos altamente profesionalizados dentro de una burocracia estatal ajustada a un ordenamiento legal en el cual creyera o se sometiera voluntariamente el conjunto de la sociedad. La efectividad del vínculo entre saber especializado, "racionalidad instrumental” y "poder” volvía a verificarse en la realidad.

Las conductas humanas que cimentaron la crisis financiera mundial, que fueron la ambición desmedida, la estafa, el engaño y el deseo de riqueza fácil aprovechándose del más débil, pueden ser, sin lugar a dudas, interpretadas como una "regresión primitiva" de un fenómeno de masas con una conducción similar a la de la "horda primitiva”: el "poder" autoritario concentrado en los círculos que controlaban la información financiera mundial aplasta a los demás miembros de la horda sin contemplaciones morales. Los instintos de "agresión” naturales en el ser humano, descritos por Freud, hicieron aquí su entrada triunfal en un escenario sin una conducción que combinara la "ética de los principios" con la "ética de la responsabilidad" hasta que el sistema debió nuevamente ser regulado por el "saber especializado" del "poder" burocrático internacional, dirimiendo el caos de los múltiples "conflictos de intereses” en juego.

En resumen, podría plantearse, que las tesis acerca de la esencia del fenómeno del "poder", sus formas de expresión y su base antropológica, descrita por nuestros tres clásicos: Weber, Freud y Kelsen no han perdido su validez hasta el día de hoy por varias razones:

El "nuevo paradigma científico" cambia la visión de la ciencia superando principalmente la lógica causal del paradigma newtoniano. Poniendo en el centro de las investigaciones científicas el principio de incertidumbre, de relatividad, de complejidad y del mundo de las probabilidades en vez de las certidumbres finales y causales, parte de la base que la realidad es múltiple, incierta y relativa. El hecho que Weber, Freud y Kelsen basaran sus tesis a partir de concepciones del hombre cuya base antropológica fuera similar (agresividad, ambición por el "poder", ansias de dominio y posesión, Eros) pero que actuaban sobre la base de la relatividad de los valores y la subjetividad de las visiones del mundo, los puso incluso en su época a la vanguardia de las investigaciones en cada una de sus áreas, posibilitando entender múltiples escenarios probables dentro de la compleja conducta humana en torno a las relaciones de "poder" como son: el sometimiento, la dominación, el temor, la adoración, la tiranía, la obediencia, la disciplina, los tipos de liderazgo, la relación entre masas y conductores, entre conflicto individual y colectivo.

La racionalidad de sus investigaciones tuvo presente que los fenómenos del "poder” y de la organización social era obra humana y por tanto sujetos a cambios inesperados debido a la imposibilidad de otorgar algún valor absoluto a las distintas subjetividades. Ellos generaron diversas metodologías para comprender estas situaciones, pero lo común a los tres fue que subrayaron la necesidad de crear mecanismos normativos de la 
conducta humana desde el psicoanálisis, la sociología y el derecho, con la finalidad de hacer prevalecer una cultura proclive a la regulación de los conflictos.

Es evidente que en la actual etapa de desarrollo de la sociedad de la información, las formas del ejercicio del "poder” y sus canales de distribución adoptan nuevas formas, nuevas velocidades e integran nuevas temáticas y actores. Incluso el propio Estado renueva su institucionalidad adoptando muchas de las características propias de los "sistemas adaptivos complejos" (multiplicidad de componentes, relaciones asimétricas, mecanismos retroalimentadores, desarrollo de patrones propios de conducta, incertidumbre dentro de cierta estabilidad, apertura) y comienza a organizarse en forma de redes dentro de las relaciones de "poder" tradicional establecidas. El mismo Estado moderno busca la interacción con múltiples actores que antes de la era de la información no hubiesen tenido ninguna posibilidad de interactuar desde sus redes a partir de sus intereses.

Las tesis acerca del nuevo carácter de las relaciones de "poder" que se conformarían a partir del modo en que se organizan ( en este caso en redes), y que posibilitarían la prevalencia de las relaciones empáticas en las actividades humanas basadas en la negociación, persuasión y autonomía, de alguna manera adquieren ciertos rasgos utópicos, pues si esto fuera cierto, la "red" y sus poderes se transformarían en sí en un camino de convivencia pacífica entre los seres humanos, donde sus naturales instintos agresivos no jugarían ningún papel.

En relación con la cuestión del "poder" en el marco del "nuevo paradigma científico”, el esfuerzo analítico que se requiere en América Latina es doble si consideramos que en primer lugar se debe estudiar la medida real de la difusión del nuevo paradigma científico sobre el mundo de la ciencia en nuestro continente y en segundo lugar la probabilidad que éste penetre el pensamiento político de las élites e influencie las conductas de las masas organizadas y espontáneas. En este marco, la relectura de Weber, Freud y Kelsen se hace imprescindible a la hora de intentar comprender la complejidad propia de los fenómenos del "poder” que son y serán básicamente una relación humana en que uno manda y el otro obedece sobre la base de valores subjetivos. La estructura de cómo se dé este fenómeno, sus condicionamientos históricos y sus formas de regulación seguirán adoptando las más diversas modalidades y el intento de “comprenderlos” desde el punto de vista weberiano, libre de juicios de valor, será naturalmente un desafío para las ciencias sociales.

\section{Apuntes sobre la validez de Weber, Freud y Kelsen en América Latina}

Luego de presentar brevemente en los capítulos anteriores las tesis desarrolladas por nuestros tres autores en torno a la cuestión del "poder", resulta interesante la pregunta sobre la validez o aplicabilidad de estos 
pensamientos a América Latina, porque la historia política moderna de nuestro continente se ha orientado principalmente por el modelo de desarrollo occidental de la sociedad de libre mercado, ya sea en forma "negativa", rechazándolo, o bien en forma “positiva” intentando imitarlo.

No pretendemos una respuesta integral a esta interrogante, no obstante intentaremos aproximarnos a ella analizando tres elementos fundamentales de los enfoques presentados: la predominancia de la "racionalidad instrumental”, el control de la violencia y el rol del "estado de derecho” democrático como condición para el desarrollo cultural en occidente.

Para cualquier lector que conozca la historia moderna de América Latina, no resulta difícil comprobar que la constelación descrita por Max Weber en torno a la "predominancia” de la "racionalidad instrumental" en todos los ámbitos de la vida no ha podido consolidarse en lo que el llamaba un "estilo de vida racional” promedio para todos. Si bien es cierto que la lógica instrumental avanza en las áreas punta de ciertas ramas productivas ligadas a los mercados internacionales, este estilo de organización basado en el logro de resultados según un plan claramente establecido no logra penetrar las tradiciones fuertemente arraigadas en América Latina. Cuando Weber hablaba del peligro que conlleva el "diletantismo" en la administración pública para el desarrollo de las sociedades capitalistas, en cuanto a desperdicio de recursos, abuso de “poder” y obstáculos para resolver los problemas básicos de la población, especialmente la de aquella aglomerada en ciudades, no duda en calificar a la burocracia legal con su lógica instrumental como la mejor solución de gestión conocida hasta el momento. La infinita cantidad de estudios existente acerca de las dificultades que ha tenido América Latina para resolver cuestiones fundamentales del desarrollo moderno hasta el día de hoy, nos ofrecería múltiples datos acerca de esta realidad que aquí no viene al caso citar.

Lo que parece evidente es que en América Latina pareciera haberse instalado otra combinación de racionalidades, cuya predominancia ha determinado la situación actual dentro del mundo. El peso de la creencia en valores absolutos de carácter religioso o ideológico, la desconfianza frente a las instituciones del Estado , la tendencia a seguir ciertos líderes de corte mesiánico, la negación de la existencia de estilos de vida basados en cosmovisiones diferentes, la prevalencia de fuertes rasgos misóginos en la cultura latina $^{66}$ y otra serie de factores culturales han tendido a consolidar en vastos territorios más bien los tipos de racionalidad que Weber atribuía a las formaciones económicas anteriores al capitalismo moderno, tales como la "racionalidad según los valores", la "racionalidad según los afectos" o la “racionalidad según la tradición”. Como vimos anteriormente, estas racionalidades se caracterizan por el hecho de tener objetivos preconcebidos y rígidos, no dando ningún espacio para su revisión ni el descarte de los medios violentos para conseguirlos si fuera necesario. Si bien es cierto que partes de América Latina se acercan en mayor grado al tipo de constelación cultural que determinó el desarrollo de las sociedades modernas occidentales más avanzadas quedan todavía muchos países donde ha sido muy 
difícil incluso asegurar el monopolio de la coerción física en manos del Estado como son los casos de Colombia, México, Guatemala, El Salvador y otros.

No dejaría de ser interesante investigar cuál es la combinación weberiana de "racionalidades" que se da en los distintos países de América Latina y sobre esa base compararlos con sus niveles de desarrollo. Al menos nos ayudaría a entender "por qué la situación es así y no de otra manera” para hablar con las palabras de Weber.

En relación con el control de la violencia, condición fundamental para la convivencia civilizada según Freud, América Latina ha realizado grandes esfuerzos por regular la conducta humana a través del Estado y de la ley. Los escenarios de organización social y política de la región nos presentan, no obstante, una variada gama de sistemas normativos. No debe olvidarse que América Latina vivió su propia regresión a la "horda primitiva” en el sentido freudiano, cuando a partir de principios de los setenta hasta mediados de los ochenta se desató la ola de dictaduras militares cuyo principal fin era la conservación del estatus quo a través de la violencia y la más extrema intolerancia. Recién a partir de los noventa se inicia la transición a la democracia y aumentan los niveles de tolerancia entre diferentes ideologías. Una expresión de esta constelación fue la pacificación de los países en situación de guerra civil durante los años ochenta en Centroamérica, el término de la década de las dictaduras militares y el aumento de la conciencia acerca de la necesidad de luchar contra las desigualdades sociales como fuentes generadoras de violencia. Parte importante de las elites políticas muestran una voluntad civilizatoria en el sentido de promover la paz social.

Sin embargo, prevalece todavía una persistente situación de violencia cuyas caras son múltiples: altas tasas de homicidios, tráfico de drogas, de órganos, de personas, feminicidios, corrupción, pandillerismo, secuestros y masacres, entre otros. Según el último Informe de Desarrollo Humano para América Central 2009-2010 del PNUD ${ }^{67}$, esta región es la más violenta del mundo con una tasa promedio de homicidios de 33 por 100.000 habitantes, tres veces más en comparación con la tasa mundial que es de 11 cada 100.000 habitantes. Si bien es cierto que la situación varía por países en América Latina, Chile, Uruguay y Argentina los países más pacíficos de la región, con 1, 4 y 5 homicidios por cada 100.000 habitantes, estas cifras se disparan a 66 en El Salvador, a 47 en Guatemala y a 37 en Colombia. El resultado es que en vastos territorios de América Latina todavía la cuestión civilizatoria pasa por resolver el problema del manejo de la violencia en forma eficaz por parte del Estado.

A partir de los noventa los regímenes de transición a la democracia en América Latina reformaron las constituciones de las repúblicas sin que se tocara la larga tradición del presidencialismo con amplios poderes de veto y el consiguiente debilitamiento del parlamento. Kelsen ya había calificado este presidencialismo como pernicioso para el desarrollo de un Es- 
tado de derecho tolerante. Sin embargo, a la luz de las experiencias autoritarias, en casi todas estas constituciones se prohibió la reelección seguida de los presidentes para evitar que se eternizaran en las estructuras del poder. Esta prohibición ha sido, no obstante, materia de reformas un muchos países $^{68}$ como Venezuela, Ecuador, Colombia, Argentina, Bolivia y Brasil donde se ha tendido a identificar el éxito de los procesos políticos con un caudillo-presidente.

El rol del Estado en la región ha sufrido fuertes cambios durante estas últimas décadas y es recién en este siglo, donde se comienza a consolidar la idea de un Estado de derecho como único ordenamiento regulador de la vida social. Los procesos de modernización del Estado llevados a cabo durante los ochenta y noventa ${ }^{69}$ contribuyeron a aumentar la conciencia sobre la necesidad de una continuidad en la administración del Estado. Así, por ejemplo en Chile, en Brasil, en Uruguay y en Argentina. A pesar que los procesos de reforma se iniciaron por presión externa en el marco de la alta deuda externa adquirida durante los ochenta y la presión por resolver las deficiencias en la entrega de servicios públicos de calidad en los noventa, ellos lograron sentar las bases para un nuevo tipo de relacionamiento entre el Estado y los ciudadanos. Las relaciones de "poder” parecían redefinirse en torno al empoderamiento de las organizaciones ciudadanas, a la conciencia sobre los derechos del consumidor y los deberes que le cabían al Estado en estas materias. El grado de avance de estos cambios dependía y depende todavía del peso de las tradiciones autoritarias a nivel cultural y político, del clientelismo profundo que había existido tradicionalmente en el servicio público y de la voluntad de las elites de gobierno en superar estas debilidades ${ }^{70}$.

Considerando la diversidad política actual en América Latina, donde hay Estados que conviven con distintos ordenamientos normativos, podemos afirmar que el ideal de Kelsen de la eficacia del Estado de derecho como ente regulador en todas las áreas de la actividad humana todavía pugna por abrirse paso. Ejemplos de esta situación son: Colombia, donde hace sesenta años se gobierna con la existencia de varios ejércitos armados paralelos a los regulares ${ }^{71}$; México que se enfrenta a la explosión de sistemas de criminalidad organizada ${ }^{72}$ en torno al narcotráfico y otras actividades delincuenciales que ponen en jaque el control del territorio nacional y la seguridad de su población; o bien Centroamérica, donde actúan pandillas criminales ${ }^{73}$ que dominan barrios, ciudades y territorios completos sobrepasando en número de miembros a las Fuerzas Armadas y la Policía. El monopolio legítimo de la coerción física por parte del Estado de derecho, condición fundamental de la modernidad estatal según Weber y Kelsen, no ha logrado consolidarse eficazmente en muchos países de América Latina a pesar de los avances logrados.

Concluyendo, la introducción de la "racionalidad instrumental" como racionalidad predominante en la sociedad, la consolidación general del Estado de derecho democrático en todo el territorio así como el control eficaz de la violencia a través de un sistema normativo único, son hasta 
ahora desafíos por alcanzar en América Latina, si es que estos criterios fueran considerados como válidos por sus líderes políticos y económicos, las organizaciones sociales y la ciudadanía.

\section{Consideraciones finales}

La revisión del fenómeno del "poder” desde sus vertientes sociológicas, psicoanalíticas y jurídicas nos hace tener presente que las "relaciones de "poder"” entre los seres humanos pueden adoptar distintas formas, usar distintos medios y tener distintos fines y patrones de distribución, pero en su composición y esencia permanecen igual: Una relación de mando y obediencia basándose en un valor subjetivo. Hasta ahora no hay ningún mecanismo científico que compruebe empíricamente el valor absoluto de una relación de "poder", por lo que su fuente de legitimación siempre será subjetiva.

Aceptando este hecho Weber, Freud y Kelsen coincidieron en que el ser humano se caracterizaba en forma natural por sus instintos agresivos y que la condición para la construcción de una vida civilizada era la regulación de la conducta humana.

Este pensamiento sigue siendo vigente y no ha podido ser rebatido hasta ahora por ninguna evidencia empírica relevante. Si bien Weber planteaba que la burocracia legal predominante en occidente moderno generaba un tipo de "poder desencantado", reconocía que era el más eficaz hasta ahora conocido, aunque no respondiera a la pregunta existencial del hombre sobre el sentido de su vida.

Si observamos al hombre moderno, podremos ver en él el temor de verse reducido a ser un rodamiento más en la maquinaria burocrática con posibilidades limitadas de autodeterminación, pero al mismo tiempo percibiremos un cierto efecto compensatorio al recibir todo tipo de servicios básicos que antes debían ser obtenidos con mucho esfuerzo por cada individuo. Pareciera ser que la búsqueda de la felicidad no le resultara urgente. Es probablemente de esta manera como la mayoría de las personas se conforman y comienzan a cambiar su felicidad por la seguridad, a descansar en la regulación externa de la conducta en vez de usar su chance de desenvolverse libre y autónomamente y termina reemplazando el placer por una reducción del sufrimiento. Quizás este mecanismo compensatorio podría explicar por qué muchos individuos no sienten la necesidad de hacer uso activo de su libertad, o bien ni siquiera tienen conciencia de esta posibilidad. No obstante, el "malestar" de la cultura no desaparece, sino que queda , en el mejor de los casos, latente. Esperanzador resulta de todas maneras el hecho que aquellos que optan por darle a su existencia un sentido personal, social y libre en medio de la maquinaria reguladora, puedan encontrar sus espacios presionando por su continua modificación en favor de las mayorías por ser justamente un producto de la acción del ser humano susceptible de cambiar o reemplazar dentro del estado de derecho. 
Si sumáramos las características de los prototipos de hombre moderno que propusimos al principio de este ensayo para nuestros tres autores en uno sólo, el cuadro que obtendríamos sería el de un sujeto civilizado y racional pero con tendencia a la neurosis. Por esta razón su relación con el "poder" es distorsionada. Por un lado quiere su libertad, pero por el otro busca ser parte del colectivo por su natural instinto de sobrevivencia. El hombre promedio de la masa espontánea, como nos decía Freud, quiere ser dominado y vivir la ilusión de la armonía con su conductor para escaparse de la responsabilidad sobre su existencia y darle rienda suelta a sus impulsos innatos. No resulta extraño entonces la explosión de conductas irracionales, tales como la xenofobia, la misoginia, la intolerancia política y la violencia de partes importantes de la población, en medio de la cultura occidental hasta el día de hoy. En contraposición, también se registra una importante intolerancia frente a estas tendencias de hostilidad social.

Las bondades de la interacción entre democracia y Estado de derecho, descritas por Kelsen, que permitirían desarrollar las mejores técnicas para dirimir los "conflictos de poder", parecieran tener eficacia general solamente en aquellos países donde predomina efectivamente la racionalidad instrumental en todos los ámbitos de la vida social en el sentido weberiano.

En América Latina hemos visto durante las últimas décadas esfuerzos importantes de modernización del Estado y de racionalización instrumental de la gestión pública con resultados de la más distinta índole. Lo que resulta evidente es que en algunos países las estructuras del "poder" han tendido a dispersarse y de ninguna manera responden a un ordenamiento jurídico único, aunque exista la pretensión del monopolio de la violencia física por parte del Estado.

La cuestión de las relaciones de "poder” entre los individuos y el Estado parece encontrarse en un estadio de redefinición, donde las diversas subjetividades pugnan por encontrar su lugar en la sociedad. El consenso acerca de la validez legítima de cada subjetividad todavía tiene un largo camino que recorrer. Baste recordar el reciente golpe de estado en Honduras (2009), el intento de golpe en Ecuador (2010) y las luchas de los pueblos indígenas en contra de la discriminación racial que sufren en pleno siglo XXI.

Las nuevas formas de organización social en redes y altamente interconectadas han alimentado las esperanzas de un mundo, donde los canales de diálogo fomentarían un modo de vida civilizado entre seres humanos desde los más distintos rincones de la tierra. La información y el conocimiento empoderarían a estos sujetos hacia nuevas formas de participación política en torno a intereses autónomos que pondrían en jaque a los núcleos tradicionales del "poder" como son el Estado y sus instituciones. El rol de los líderes tradicionales sería reemplazado por el "poder” distribuido en las redes sociales y con ello se reducirían los peligros de los esta- 
llidos autoritarios. Hasta ahora estas ideas se quedan todavía en el mundo de las especulaciones, pues no están comprobadas empíricamente.

Lo que se observa claramente es que los nuevos escenarios del "poder” serán cada vez más impredecibles e inciertos. Probablemente las influencias que tradicionalmente se ejercían a largo plazo y en forma constante sobre la opinión pública desde las organizaciones más "poderosas ${ }^{74}$, tenderán a relativizarse al ritmo en que las redes sociales propongan temas que intercepten el flujo normal de información oficial y creen espacios de influencia espontáneos, intermitentes e inestables, pero eficaces a la hora de emitir mandatos o bien lograr que sus miembros obedezcan. La competencia entre estos tipos de "poder" ya está en curso hace mucho tiempo, aunque nada indique que ésta conduzca hacia la eliminación de uno de estos polos, sino que más bien tiendan hacia una convergencia. El carácter de esta nueva convergencia dependerá seguramente de la probabilidad de ganar legitimidad por parte de las redes y de captar preferencias obligando al Estado a compartir espacios tradicionales de influencia. La evidencia empírica ha demostrado recientemente que solamente la unicidad de los mecanismos regulatorias de las conductas humanas logra aplacar efectivamente la natural tendencia del ser humano hacia la agresividad. Ejemplos de ello son la regulación de los delitos ambientales, financieros internacionales y los conflictos bélicos. En qué medida la efectividad de esta unicidad regulatoria podrá ir integrando subjetividades emergentes para prevenir nuevos conflictos dependerá del grado de tolerancia de las elites tradicionales frente a la diversidad de valores. Porque ya Kelsen lo decía: mientras más ansias de "poder", menor es el aprecio por la libertad y mayor la probabilidad de conductas autoritarias.

En este contexto, la interpretación multidisciplinaria del fenómeno del "poder" se agiliza y enriquece con la magnífica obra de Weber, Freud y Kelsen que en su conjunto está a la altura de las exigencias del "nuevo paradigma científico”. 


\section{Notas}

1 “Libido” se refiere a los lazos afectivos de toda índole más allá del acto amoroso.

${ }^{2}$ El concepto de "horda primitiva” la tomó Freud de Darwin y se refiere a que la forma primitiva de la sociedad humana habría sido la de horda sometida al dominio absoluto de un poderoso macho que sometía a los demás por medio de la violencia. Véase: Freud, Sigmund: Psicología de las masas y el análisis del yo. (1920-1921) . En: http:// filosofiacotidiana.files.wordpress.com/2010/03/psicologia-de-las-masas-y-analisis-delyo.pdf , pág.41.

${ }^{3}$ Entre estos autores se pueden mencionar a Sandor Ferenczi, Jacques Lacan, Melanie Klein y Wilfred Bion. Véase: http://es.wikipedia.org/wiki/Sigmund_Freud

${ }^{4}$ Cuando Kelsen hace esta diferencia abre la posibilidad que los órdenes normativos sean establecidos o anulados, es decir que ellos adquieran y/o pierdan su validez. Solo la "norma básica” ( Grundnorm, véase pié de pag. № 27) es estática ya que representa la base de la estructura del derecho puro o positivo. Véase en: Schmill Ordóñez, Ulises: El concepto del derecho en las teorías de Weber y Kelsen. En: http://www.bibliojuridica.org.libros/2/970/ 9.pdf , pág. 139.

${ }^{5}$ En su obra “ Dios y el Estado” escrita en 1922-1923, Kelsen planteó que : “... el Estado es siempre Estado de derecho” y que “...el orden estatal es idéntico al jurídico”. Véase: Kelsen, Hans: Dios y el Estado. En: www.bibliojuridica.org/libros/2/970/13.pdf , pág. 255.

${ }^{6}$ Kelsen, Hans: ¿Qué es la justicia?, Viena, 1953. En: www.usma.ac.pa/web/DI/.../ Hans\%20Kelsen.\%20La\%20Juticia.pdf , pag. 21

${ }^{7}$ Véase: Bobbio, Norberto: Kelsen y Max Weber. En: www.bibliojuridica.org/libros/2/970/ 5.pdf , pág. 74. Para conocer con más profundidad las aristas de esta controversia léase: Kelsen, Hans: El Concepto del Estado de la sociología comprensiva, 1921. En: www.bibliojuridica.org/libros/2/970/14.pdf

${ }^{8}$ Weber no estaba de acuerdo con el pronóstico de futuro que se derivaba del Manifiesto Comunista de Carlos Marx (1847), sin embargo el mismo reconoció que Marx había hecho un aporte científico de primer nivel en sus análisis sociales y económicos del capitalismo. Véase: Weber, Max: Schriften zur Soziologie und Sozialpolitik. Der Sozialismus. (1918). En: http://www.zeno.org/Soziologie/M/Weber,+Max/Schriften+zur+Soziologie+und+ Sozialpolitik/Der+Sozialismus, pág. 505.

${ }^{9}$ Véase: Weber, Max: Legale Herrschaft mit bürokratischem Verwaltungsstab. En: Weber, Marianne: Wirtschaft und Gesellschaft, (1925). En: http://www.zeno.org/Soziologie/M/ Weber,+Max/Grundri\%C3\%9F+der+Soziologie/Wirtschaft+und+Gesellschaft/ Erster+Teil.+Soziologische+Kategorienlehre/Kapitel+III.+Die+Typen+der+Herrschaft/ 2.+Die+legale+Herrschaft+mit+bureaukratischem+Verwaltungsstab, págs. 126-127.

${ }^{10}$ Véase: Weber, Max: Bestimmungsgründe sozialen Handelns. En: http://www.zeno.org/ Soziologie/M/Weber,+Max/Schriften+zur+Wissenschaftslehre/Soziologische+Grundbegriffe pg. 1.

${ }^{11}$ Citado de las obras completas de Max Weber por: Jonas, Friedrich: Geschichte der 
Soziologie 2. Von der Jahrhundertwende bis zur Gegenwart. 2te. Auflage, Hamburg, 1981, pág. 186.

${ }^{12}$ Véase: Weber, Max: Gesammelte Aufsätze zur Religionssoziologie. Band 1, 6. Auflage, Tübingen, 1971, pág. 203. citado por: Müller, Hans Peter: Max Weber. Eine Einführung in sein Werk, Köln, 2007, pág. 103.

${ }^{13}$ Smith, Adam: The Theory Of Moral Sentiments. Part Third. Of The Foundation Of Our Judgments Concerning Our Own Sentiments And Conduct, And Of The Sense Of Duty. London, 1853, pág. 194.

${ }^{14}$ Op.cit: pág. 206.

${ }^{15}$ La relación entre autocontrol y la posibilidad de alcanzar mayores niveles civilizatorios, la describía Adam Smith de la siguiente manera: “ The man who feels the most for the joys and sorrows of others, is best fitted for acquiring the most complete control of his own joys and sorrows. The man of the most exquisite humanity is naturally the most capable of acquiring the highest degree of self-command”. Op.cit. pág. 214.

${ }^{16}$ Weber, Max: Politik als Beruf. 1919. Reclams Universal Bibliothek Nr. 8833, Stuttgart, 1992. pág. 79. Léase el texto original: “... der Dämon der Politik lebt mit dem Gott der Liebe,..., in einer inneren Spannung, die jederzeit in unaustragbarem Konflikt ausbrechen kann“.

${ }^{17}$ Véase op.cit: pag. 81.

${ }^{18}$ Véase: Freud, Sigmund: Psicología de las masas y el análisis del yo. (1920-1921) . En: http://filosofiacotidiana.files.wordpress.com/2010/03/psicologia-de-las-masas-y-analisis-delyo.pdf , pág.1.

${ }^{19}$ Freud, Sigmund: El malestar en la cultura. Traducido del texto original "Das Unbehagen der Kultur” (1929-1930), En: http://isaiasgarde.myfil.es/get_file?path=/freud-sigmundmalestar-en-la-cu.pdf , pág. 42

${ }^{20}$ Véase, op.cit: pág. 41.

${ }^{21}$ Ibíd: pág. 30.

${ }^{22}$ Conviene aquí destacar como entendía Freud el concepto de neurosis: "La neurosis venía a ser la solución de una lucha entre los intereses de la autoconservación y las exigencias de la líbido, una lucha en la que el yo , si bien triunfante, había pagado el precio de graves sufrimientos y renuncias”. Véase: : Freud, Sigmund: El malestar en la cultura. Traducido del texto original “Das Unbehagen der Kultur” ( 1929-1930), 2002. En: http:// isaiasgarde.myfil.es/get_file?path=/freud-sigmund-malestar-en-la-cu.pdf , pag. 29.

${ }^{23}$ Freud, Sigmund: El malestar en la cultura. Traducido del texto original "Das Unbehagen der Kultur” ( 1929-1930), 2002. En: http://isaiasgarde.myfil.es/get_file?path=/freudsigmund-malestar-en-la-cu.pdf pag. 15.

${ }^{24}$ Freud, Sigmund: op.cit. , pág. 43. 
${ }^{25}$ Véase: Villacañas Berlanga, José Luis: Qué sujeto para qué democracia. Un análisis de las afinidades electivas entre Freud y Kelsen. En: LOGOS. Anales del Seminario de Metafísica, Vol. 35 , págs. 11-45, aquí: pág. 44., 2002.

${ }^{26}$ Kelsen, Hans: ¿Qué es la Justicia?, Viena, 1953, pág. 9-10.En: http://www.usma.ac.pa/ web/DI/images/Eticos/Hans\%20Kelsen.\%20La\%20Juticia.pdf

${ }^{27}$ Esta norma fundamental ( Grundnorm) suele representarse como un triángulo conformado en cada uno de sus ángulos con un actor y una función. En el ángulo inferior a la izquierda está el "sujeto con derechos positivos" (A); en el ángulo inferior a la derecha está el "sujeto con un deber positivo" (B) y en el ángulo superior está "la autoridad competente con funciones juridiccionales" (C). Estos tres ángulos se relacionan de la siguiente forma: A tiene un derecho subjetivo ante el incumplimiento del deber jurídico de $\mathrm{B}$ por lo que solicita a C, se aplique la sanción. C ejecuta la sanción a B y de esta manera consecutivamente. Cada norma es parte de una construcción jerárquica que tiene significado dentro de un conjunto complejo y único y que dan lugar a un ordenamiento jurídico coherente con sus propias reglas de autoproducción, vigencia y derogración. Véase: Filosofía del Derecho: Hans Kelsen: Teoría Pura del derecho. En: http://aquileana.wordpress.com/2007/12/11/hanskelsen/

${ }^{28}$ Salazar Ugarte, Pedro: Nota sobre democracia y constitución en la obra de Hans Kelsen. En: ISONOMIA Nro. 28, México, Abril 2008, págs. 187-197, aquí pág. 192. En : http:// descargas.cervantesvirtual.com/servlet/SirveObras/01394931900460537647802/ 033821.pdf?incr=1

${ }^{29}$ Schmill Ordóñez, Ulises: El concepto del derecho en las teorías de Weber y Kelsen. En: www.juridicas.unam.mx/publica/librev/rev/boletin/cont/.../art5.pdf , pág. 120.

${ }^{30}$ Para un estudio más en profundidad de las diferencias conceptuales acerca de Estado y derecho en Weber y Kelsen, Véase: Kelsen, Hans: El concepto de Estado de la sociología comprensiva, 1921. En: www.bibliojuridica.org/libros/2/970/14.pdf

${ }^{31}$ Kelsen, Hans: El concepto del Estado y la Psicología Social. Teniendo como referencia especial la teoría de las masas según Freud. En: http://www.bibliojuridica.org/libros/2/970/ 17.pdf , 1922, pág. 371.

${ }^{32}$ Véase: Squella, Agustín: Idea de la Democracia en Kelsen. En: www.cepchile.cl/dms/ archivo_1073_914/rev13_squella.pdf

${ }^{33}$ Véase: Kelsen, Hans: Wesen und Wert der Demokratie. Conferencia dictada el 5.11. de 1919. pág. 2 y 3. En: www.wjg.at/docs/wesen.doc.

${ }^{34}$ El profesor de filosofía Villacañas Berlanga denomina seguramente por esta razón al prototipo de hombre kelnesiano "hombre democrático" . Véase: Villacañas Berlanga, José Luis: Qué sujeto para qué democracia. Un análisis de las afinidades electivas entre Freud y Kelsen. En: LOGOS. Anales del seminario de Metafísica, Vol. 35, 2002, sin lugar, págs. 1154. En: http://dialnet.unirioja.es/servlet/articulo?codigo=302018

${ }^{35}$ Véase: Montbrun, Alberto: Notas para una revisión crítica del concepto del “poder”. En: POLIS, Revista de la Universidad Bolivariana, Volumen), N²5, 15.01.2010, págs. 367389. En: http://www.scielo.cl/pdf/polis/v9n25/art22.pdf . Aquí Montbrun cita el trabajo del 
profesor de la Facultad de Ciencias Políticas de la Universidad Nacional de Córdova Walter Cueto, donde resume 10 definiciones de poder que ilustran nuestra apreciación e incluyen: Robert Dahl, David Easton, Carl Friedrich, Raymond Aron, Harol Laswell y Abraham Kaplan, Richard Schemerhorn, Amitai Etzioni, Eduard Spranger, Julien Freund y Karl Deutsch.

${ }^{36}$ Weber, Max: Macht und Herrschaft. Übergangsformen, primer capítulo de Grundriß der Soziologie en: Weber, Marianne (ed.) Wirtschaft und Gesellschaft, 1925. Pág. 541. En: http://www.zeno.org/Soziologie/M/Weber,+Max/Grundri\%C3\%9F+der+Soziologie/ Wirtschaft+und+Gesellschaft/Zweiter+Teil.+Die+Wirtschaft+und+die+gesellschaftlichen+ Ordnungen+und+M\%C3\%A4chte/Kapitel+IX.+Soziologie+der+Herrschaft/1.+Abschnitt.+ Strukturformen+und+Funktionsweisen+der+Herrschaft/\%C2\%A7+1.+Macht+ und+Herrschaft.+Uebergangsformen

${ }^{37}$ Tolstoi, Leo: Volkserzählungen. Reclams Universal Bibliothek, Stuttgart 2005, pág. 254. Traducida del alemán "Was sollen wir denn tun?”.

${ }^{38}$ Gustave Le Bon ( 1841-1931) , médico, psicólogo y sociólogo francés, precursor del estudio de las conductas colectivas de los individuos. En 1895 publicó “ La psicología de las masas. Estudio sobre la psicología de las multitudes” que sentaría las bases para el estudio de esta temática a nivel universal y sobre la cual Freud basó sus propias investigaciones.

${ }^{39}$ Le Bon, Gustave: Psicología de las Masas. Citado por Freud en: Freud, Sigmund: Psicología de las masas y el análisis del yo. (1920-1921) . En: http://filosofiacotidiana.files. wordpress.com/2010/03/psicologia-de-las-masas-y-analisis-del-yo.pdf , págs. 9-10.

${ }^{40}$ Véase, Op. Cit: pág. 10

${ }^{41}$ Weber, Max: : Politik als Beruf. 1919. Reclams Universal Bibliothek Nr. 8833, Stuttgart, 1992.

${ }^{42}$ Correas, Oscar: El otro Kelsen. Pág. 31. Universidad Autónoma de Puebla, México. En: http://www.bibliojuridica.org/libros/2/970/4.pdf

${ }^{43}$ Weber, Max: Politik als Beruf. 1919. Reclams Universal Bibliothek Nr. 8833, Stuttgart, 1992. pág.7

${ }^{44}$ Op. Cit. Pág. 13.

${ }^{45}$ Weber, Max:op.cit.

${ }^{46}$ Véase: Weber, Max: Schriften zur Wissenschaftslehre. Soziologische Grundbegriffe. Arten der legitimen Ordnung: Konvention und Recht. En: http://www.zeno.org/Soziologie/M/ Weber,+Max/Schriften+zur+Wissenschaftslehre/Soziologische+Grundbegriffe/ \%C2\%A7+VI.+Arten+der+legitimen+Ordnung\%3A+Konvention+und+Recht, pág. 576.

${ }^{47}$ Esas investigaciones se refieren al médico psiquiatra y sociológo Gustave Le Bon ( 18411931) de Francia, al jurista italiano Escipión Sighele (1868-1913) que escribió "La Muchedumbre delincuente. Ensayo de Psicología Colectiva” en 1892, a William Mc. Dougall (18711938) psicólogo inglés que escribió “The Group Mind” en 1920 y a Wilfred Trotter (1872- 
1939) neurocirujano inglés cuya obra más destacada fue Instincts of the Herd in Peace and War.

${ }^{48}$ Véase: Freud, Sigmund: Psicología de las masas y el análisis del yo. (1920-1921) En: http://filosofiacotidiana.files.wordpress.com/2010/03/psicologia-de-las-masas-y-analisis-delyo.pdf , pág. 20.

${ }^{49}$ El concepto de „instinto gregario” del ser humano fue acuñado por el neurocirujano inglés Wilfred Trotter. Véase cita $\mathrm{Nr}^{\circ} 46$ de esta lista.

${ }^{50}$ Véase: Freud, Sigmund: Psicología de las masas y el análisis del yo. (1920-1921) En: http://filosofiacotidiana.files.wordpress.com/2010/03/psicologia-de-las-masas-y-analisis-delyo.pdf , pág. 41 .

${ }^{51}$ Kelsen, Hans: El concepto del Estado y la Psicología Social. Teniendo como referencia especial la teoría de las masas según Freud. En: http://www.bibliojuridica.org/libros/2/970/ 17.pdf , 1922, pág. 357.

${ }^{52}$ Véase Op.cit. pág. 370.

${ }^{53}$ Véase: Kelsen, Hans: Dios y el Estado. 1922-1923. En: http://www.bibliojuridica.org/ libros/2/970/13.pdf , pág. 255.

${ }^{54}$ Véase: Montbrun, Alberto: Notas para una revisión crítica del concepto del "poder”. En: POLIS, Revista de la Universidad Bolivariana, Volumen), №25, 15.01.2010. En: http:// www.scielo.cl/pdf/polis/v9n25/art22.pdf. , págs. 367-369.

${ }^{55}$ Véase: Rojo, Raúl, E.: Por una sociología jurídica del poder y la dominación. En: Sociología, Porto Alegre, año 7, No 13, jan/jun, 2005, En: http://www.scielo.br/pdf/soc/n13/ 23556.pdf , pág. 70

${ }^{56}$ Albert Einstein ( 1879-1955) , físico alemán, nacionalizado norteamericano. Entre sus obras principales se encuentran "Las Bases de la Teoría General de la Relatividad” ( 1916); Geometría y Experiencia (1921) y el Significado de la Relatividad (1945). Se considera uno de los genios del siglo XX ya que marcó el paso de la física clásica a la de la relatividad con múltiples efectos sobre el conocimiento acerca del origen del universo al plantear que existe la posibilidad de la desintegración de la materia. Véase: Biografías y Vidas, Albert Einstein, Nov. 2004, en: http://biografiasyvidas.com/biografia/e/einstein.htm

${ }^{57}$ Werner Karl Heisenberg (1901-1976) , físico alemán autor de la mecánica cuántica matricial basada en la teoría del físico alemán Max Planck quien fuera a su vez premio nobel de física en 1918. Heisenberg demostró el "principio de incertidumbre o de indeterminación” que comprueba que es imposible determinar en forma exacta la posición( espacio) y el momento(tiempo) de un cuerpo. A diferencia de Einstein, descubrió que las leyes de la física tenían componentes aleatorios e impredictibles. Véase: Biografías y vidas, Werner Heisenberg, Nov. 2004, en: http://biografiasyvidas.com/biografia/h/heisenberg.htm

${ }^{58}$ Véase: Montbrun, Alberto: Notas para una revisión crítica del concepto del “poder”. En: POLIS, Revista de la Universidad Bolivariana, Volumen ), N²5, 15.01.2010, págs. 367389. En: http://www.scielo.cl/pdf/polis/v9n25/art22.pdf. , págs. 367-369. 
${ }^{59}$ Heisenberg, Werner, citado por: Guerrero,Fernando: Teorías de la complejidad: un paradigma para el estudio de las organizaciones. En: http://www.monografias.com/trabajos14/ teoria-complejidad/teoria-complejidad.shtml , pág. 11.

${ }^{60}$ Op. Cit. Pág. 5.

${ }^{61}$ Algunos ejemplos son: Kurt Gödel con su “teorema de incompletitud” en 1931, Erwing Schrödinger, premio nobel de física de 1933 con su teoría de los Mundos Múltiples y la superposición de Estados, Ilya Pregonine, premio nobel de química en 1977 con su teoría del caos y otros muchos más. Véase: Guerrero ,Fernando: Teorías de la complejidad: un paradigma para el estudio de las organizaciones. En: http://www.monografias.com/trabajos14/teoria-complejidad/teoria-complejidad.shtml, págs. 7-9.

${ }^{62}$ Véase: pié de pág. $\mathrm{N}^{\circ} 53$

${ }^{63}$ Véase: Cleary, Eda: El eterno dilema del control de la gestión pública en América Latina y El Caribe. Desconfianza, control y castigo versus Confianza, verificación y estímulo. En: Biblioteca Virtual de Revista TOPde la Universidad Nacional del Litoral, Argentina, En: http://200.80.149.114/ecgp/FullText/000002/2726.pdf , págs. 15-19, Mayo 2006

${ }^{64}$ Véase: Barzelay, Michael: Diseñando el proceso de cambios en las políticas de gerenciamiento público. Doc. elaborado en el marco del diálogo regional sobre gobernabilidad y transparencia del BID.En: http://200.80.149.114/ecgp/FullText/000000/ BARZELAY\%20Michael\%20-\%20Disenando\%20el\%20proceso\%20de\%20cambio.pdf, 2001

${ }^{65}$ Véase: Cleary, Eda: El Benchmarking desde el sector privado al sector público . Apuntes sobre su aplicación en el sector público de A.L.. En: Biblioteca Virtual de Revista TOP de la Universidad Nacional del Litoral, Argentina, En: http://200.80.149.114/ecgp/FullText/ 000002/2725.pdf, págs. 1-31. El Benchmarking es un sistema de mejoramiento de procesos productivos, políticos y administrativos basados en la comparación de los mejores.

${ }^{66}$ Según la Comisión Interamericana de Derechos Humanos entre 1993 y 2009 se cometieron 7.649 asesinatos contra mujeres y niñas entre 10 y 35 años en México, de los cuales solamente 1.120 casos están siendo investigados. Véase: Feminicidios en Ciudad Juárez. En: http://es.wikipedia.org/wiki/Feminicidios_en_Ciudad_Juarez .En Guatemala se asesinaron en el mismo período un total de 5.027 mujeres y niñas según el Consejo de Ministras de la Mujer en Centroamérica y pocos de ellos se investigan. Véase: Guatemala Supera a Ciudad Juárez en la cifra de muertes violentas de mujeres. En: http://www.elmundo.es/ elmundo/2010/04/23/solidaridad/1272017355.html, 26.04.2010.

${ }^{67}$ Véase: UNDP: Informe de Desarrollo Humano para Amércia Central 2009-2010. En: http://www.undp.org.pa/centro-informacion/comunicados/presentan-informe-sobre-seguridad-ciudadana-en-america-central/3

${ }^{68}$ Negretto L., Gabriel: Paradojas de la Reforma Constitucional en América Latina. 2009. En: http://investigadores.cide.edu/gabriel.negretto/archivos/documentos/JoDEversion final2009.pdf

${ }^{69}$ Véase Oszlack, Oscar: De menor a mejor: el desafío de la segunda reforma del Estado. En: Nueva Sociedad Nº160, Venezuela, 1999, pág. 1 
${ }^{70}$ Véase: Cleary, Eda: El eterno dilema del control de la gestión pública en América Latina y El Caribe. Desconfianza, control y castigo versus Confianza, verificación y estímulo. En: Biblioteca Virtual de Revista TOP de la Universidad Nacional del Litoral, Argentina, En: http://200.80.149.114/ecgp/FullText/000002/2726.pdf , Mayo 2006. págs. 20-21.

${ }^{71}$ Durante todo el conflicto armado colombiano se calcula que la cantidad de miembros de los ejércitos irregulares como FARC y ELN variaron desde 24.000 a 10.000 efectivos y que durante el gobierno de Uribe hasta 2010 se desmovilizaron 30.000 paramilitares. Ampliamente conocido es el hecho que las FARC están involucradas en actividades delictivas como los secuestros y el narcotráfico. Véase en: http://www.elespectador.com/noticias/ politica/articulo-215214-farc-y-eln-tienen-menos-de-10000-integrantes-dice-el-gobierno. También véase: http://es.wikipedia.org/wiki/Fuerzas_Armadas_Revolucionarias_ de_Colombia

72 Según el diario El Universal del Gobierno de México, desde el año 2006 han habido 16.000 muertes y en el año 20097.724 a causas de la criminalidad y violencia. Véase en: http://www.contactomagazine.com/articulos/mexicoviolencia0110.htm

${ }^{73}$ Según cálculos basados en cifras oficiales de Naciones Unidas hasta 2008 había cerca de 70.000 pandilleros en toda América Central , cifra mayor a la de los soldados miembros de los ejércitos. Algunas ONG's hablan de hasta 200.000 miembros. En El Salvador actualmente (2010) se encuentran en prisión 7000 pandilleros maras y se calcula que entre 15.000 y 20.000 andan libres en las calles. Véase: Las Pandillas en Centroamérica. Una mafia con mil cabezas. Nuevo Diario, Managua, 11.09.2010. En: http://impreso.elnuevodiario.com.ni/ 2010/09/22/nacionales/132512 . Véase También: Pandillas y Maras en Centroamérica. Protagonistas y Chivos expisatorios. En: http://vientodelsur.wordpress.com/2008/01/23/pandillas-y-maras-en-centroamerica-protagonistas-y-chivos-expiatorios/

${ }^{74}$ El sistema de partidos políticos o las grandes corporaciones transnacionales. 


\section{Bibliografía}

Barzelay, Michael (2001), Diseñando el proceso de cambios en las políticas de gerenciamiento público. Doc. elaborado en el marco del diálogo regional sobre gobernabilidad y transparencia del BID. En: http:// 200.80.149.114/ecgp/FullText/000000/BARZELAY\%20Michael\%20\%20Disenando\%20el\%20proceso\%20de\%20cambio.pdf

Blanco, Alejandro (2007), La temprana recepción de Max Weber en la sociología argentina (1930-1950). FLACSO, México. En: http:// redalyc.uaemex.mx/pdf/115/11503001.pdf .

Bobbio, Norberto, Kelsen y Max Weber. En: www.bibliojuridica.org/libros/ 2/970/5.pdf .

Carriño, Agostino (2010), Weber y la Sociología del Derecho en la crítica de Kelsen. En: Revista Crítica Jurídica $\mathrm{N}^{\circ} 27$, Universidad de Nápoles, Enero/Julio.En: http://www.journals.unam.mx/index.php/rcj/article/view/ $16806 / 16001$

Cleary, Eda, "El Benchmarking desde el sector privado al sector público . Apuntes sobre su aplicación en el sector público de A.L.”. En: Biblioteca Virtual de Revista TOP( Técnicas para la Organización Pública) de la Universidad Nacional del Litoral, Argentina. En: http://200.80.149.114/ ecgp/FullText/000002/2725.pdf

Ídem (Mayo 2006), "El eterno dilema del control de la gestión pública en América Latina y El Caribe. Desconfianza, control y castigo versus Confianza, verificación y estímulo”. En: Biblioteca Virtual de Revista TOP(Técnicas para la Organización Pública) de la Universidad Nacional del Litoral, Argentina, En: http://200.80.149.114/ecgp/FullText/000002/ 2726.pdf

Correas, Oscar, El otro Kelsen. Universidad Autónoma de Puebla, México. En: http://www.bibliojuridica.org/libros/2/970/4.pdf

Farinetti, Marina ( 2006), "Nietzsche en Weber: Las fuentes del sentido y del sinsentido de la vida”. En: Trabajo y Sociedad N8, vol. VII, Santiago del Estero. En: http://www.unse.edu.ar/trabajoysociedad/Farinetti.pdf

Freud, Sigmund, El malestar en la cultura. Traducido del texto original Das Unbehagen der Kultur (1929-1930), En: http://isaiasgarde.myfil.es/ get_file?path=/freud-sigmund-malestar-en-la-cu.pdf

Ídem (1920-1921), Psicología de las masas y el análisis del yo. En: http:/ /filosofiacotidiana.files.wordpress.com/2010/03/psicologia-de-las-masas-yanalisis-del-yo.pdf

García González, José M., Max Weber y Georg Simmel. Dos teorías socio- 
lógicas de la modernidad? CSIC Instituto de Filosofía. Universidad de Rioja, En: http://www.jstor.org/pss/40184226, 2000.

Guerrero, Fernando, Teorías de la complejidad: un paradigma para el estudio de las organizaciones. En: http://www.monografias.com/trabajos14/ teoria-complejidad/teoria-complejidad.shtml

Herrera, Carlos M. (1997), Schmitt, Kelsen y el Liberalismo. Universidad de Cergy-Pontoise, Paris. En: http://www.cervantesvirtual.com/servlet/ SirveObras/23582844322570740087891/cuaderno21/volII/ DOXA21Vo.II_16.pdf

Jonas, Friedrich (1981), “Geschichte der Soziologie 2”. Von der Jahrhundertwende bis zur Gegenwart. 2te. Auflage, Hamburg.

Kelsen, Hans (1953), ¿Qué es la justicia?, Viena. En: www.usma.ac.pa/ web/DI/.../Hans\%20Kelsen.\%20La\%20Juticia.pdf

Ídem (1922-1923.), Dios y el Estado. En: http://www.bibliojuridica.org/ libros/2/970/13.pdf

Ídem (1921), El Concepto del Estado de la sociología comprensiva. En: www.bibliojuridica.org/libros/2/970/14.pdf

Ídem (1922), El concepto del Estado y la Psicología Social. Teniendo como referencia especial la teoría de las masas según Freud. En: http:// www.bibliojuridica.org/libros/2/970/17.pdf

Ídem, Wesen und Wert der Demokratie. Conferencia dictada el 5.11. de 1919 En: www.wjg.at/docs/wesen.doc

(1920-1921), En: http://filosofiacotidiana.files.wordpress.com/2010/03/ psicologia-de-las-masas-y-analisis-del-yo.pdf .

Martino, Antonio A. (1983), Freud, Kelsen und die Einheit des Staates. En: http://www.salvador.edu.ar/vrid/iiefgs/arti2.pdf, Bs As.

Montbrun, Alberto (2010), “Notas para una revisión crítica del concepto del 'poder' ”. En: Polis, Revista de la Universidad Bolivariana, N²5, 15.01.2010, págs. 367-389. En: http://www.scielo.cl/pdf/polis/v9n25/ art22.pdf

Müller, Hans Peter (2007), Max Weber. Eine Einführung in sein Werk, Köln.

Negretto L., Gabriel (2009), Paradojas de la Reforma Constitucional en América Latina. En: http://investigadores.cide.edu/gabriel.negretto/archivos/documentos/JoDEversionfinal2009.pdf

Oszlack, Oscar (1999), “De menor a mejor: el desafío de la segunda refor- 
ma del Estado”. En: Nueva Sociedad N 160, Venezuela.

Ídem (1980), Políticas Públicas y Regímenes Políticos: Reflexiones a partir de algunas experiencias latinoamericanas. Documentos de Estudios CEDES Vol. 3, N², Buenos Aires. En: http://www.scribd.com/doc/ 37632101/OSZLAK-Oscar-Politicas-Publicas-y-Regimenes-Politicos

Palonen, Kari (2006), La relegitimación de la democracia por Max Weber. Aspectos de la Retórica de la revisión conceptual. En: http:// saavedrafajardo.um.es/WEB/archivos/respublica/numeros/16/07.pdf

Rojo, Raúl (2005), “Por una sociología jurídica del 'poder’ y la dominación”. En: Sociología, Porto Alegre, año 7, No 13, jan/jun. En: http:// www.scielo.br/pdf/soc/n13/23556.pdf .

Romero, Aníbal (1998), Desencanto del mundo, irracionalidad étcia y creatividad humana en el pensamiento de Max Weber. En: http:// anibalromero.net/Desencanto.del.mundo.irracionalidad.etica. creatividad.humana.en.el.pdf

Salazar Ugarte, Pedro (2008), “Nota sobre democracia y constitución en la obra de Hans Kelsen”. En: Isonomia No 28, México, Abril 2008, págs. 187-197. En : http://descargas.cervantesvirtual.com/servlet/SirveObras/ 01394931900460537647802/033821.pdf?incr=1

Sánchez R., Carlos (1979), "Max Weber y la Democracia. Escenarios Aternatinos”, Crítica\&Utopía N¹, CLACSO, Bs As.

Schmill Ordóñez, Ulises, El concepto del derecho en las teorías de Weber y Kelsen. En: http://www.bibliojuridica.org.libros/2/970/9.pdf.

Smith, Adam (1853), The Theory of Moral Sentiments. Part Third. Of the Foundation of our Judgments concerning our Own Sentiments and conduct, and of the sense of Duty. London.

Squella, Agustín, Idea de la Democracia en Kelsen. En: www.cepchile.cl/ dms/archivo_1073_914/rev13_squella.pdf

Tolstoi, Leo (2005), Volkserzählungen. Reclams Universal Bibliothek, Stuttgart.

Torterola, Emiliano (2009), “Karl Löwith: una interpretación original y sugestiva de las obras de Weber y Marx”. Instituto de Altos Estudios Sociales de la Universidad Nac. Gen. San Martin, Año 2, $\mathrm{N}^{\circ}$ 5, Bs. As.

UNDP, Informe de Desarrollo Humano para América Central 2009-2010. En: http://www.undp.org.pa/centro-informacion/comunicados/presentaninforme-sobre-seguridad-ciudadana-en-america-central/3 
Villacañas Berlanga, José Luis (2002), “Qué sujeto para qué democracia. Un análisis de las afinidades electivas entre Freud y Kelsen”. En: Logos. Anales del Seminario de Metafísica, Vol. 35.

Ídem (2005), Max Weber entre Liberalismo y Republicanismo. Universidad de Murcia. En: http://docs.google.com/viewer?a=v\&q=cache: 8pml0vyWP88J:isegoria.revistas.csic.es/index.php/isegoria/article/ download/421/422+Vinacanas+Berlanga

Weber, Max, Bestimmungsgründe sozialen Handelns. En: http:// www.zeno.org/Soziologie/M/Weber, +Max/Schriften+zur+ Wissenschaftslehre/Soziologische+Grundbegriffe .

Ídem (1919), Politik als Beruf. Reclams Universal Bibliothek Nr. 8833, Stuttgart, 1992.

Ídem (1925), “Legale Herrschaft mit bürokratischem Verwaltungsstab”. En: Weber, Marianne, Wirtschaft und Gesellschaft. En: http://www.zeno.org/ Soziologie/M/Weber,+Max/Grundri\%C3\%9F+der+Soziologie/ Wirtschaft+und+Gesellschaft/Erster+Teil.+Soziologische+Kategorienlehre/ Kapitel+III.+Die+Typen+der+Herrschaft/2.+Die+legale+Herrschaft+ mit+bureaukratischem+Verwaltungsstab.

Ídem (1925), “Macht und Herrschaft. Übergangsformen”, primer capítulo de Grundriß der Soziologie en Weber, Marianne (ed.) Wirtschaft und Gesellschaft.

Ídem (1918), Schriften zur Soziologie und Sozialpolitik. Der Sozialismus. En: http://www.zeno.org/Soziologie/M/Weber,+Max/Schriften+zur+ Soziologie+und+Sozialpolitik/Der+Sozialismus.

Weber, Max, Schriften zur Wissenschaftslehre. Soziologische Grundbegriffe. Arten der legitimen Ordnung: Konvention und Recht. En:http:// www.zeno.org/Soziologie/M/Weber, +Max/Schriften+zur+ Wissenschaftslehre/Soziologische+Grundbegriffe/\%C2\%A7+VI.+ Arten+der+legitimen+Ordnung\%3A+Konvention+und+Recht

Recibido: 09.11.2010

Aceptado: 17.03.2011 